\title{
Descent and mixing of the overflow plume from Storfjord in Svalbard: an idealized numerical model study
}

\author{
I. Fer ${ }^{1,2}$ and B. Ådlandsvik ${ }^{3,2}$ \\ ${ }^{1}$ Geophysical Institute, University of Bergen, Bergen, Norway \\ ${ }^{2}$ Bjerknes Centre for Climate Research, Bergen, Norway \\ ${ }^{3}$ Institute of Marine Research, Bergen, Norway
}

Received: 16 October 2007 - Published in Ocean Sci. Discuss.: 16 November 2007

Revised: 7 April 2008 - Accepted: 7 April 2008 - Published: 6 May 2008

\begin{abstract}
Storfjorden in the Svalbard Archipelago is a sill-fjord that produces significant volumes of dense, brineenriched shelf water through ice formation. The dense water produced in the fjord overflows the sill and can reach deep into the Fram Strait. For conditions corresponding to a moderate ice production year, the pathway of the overflow, its descent and evolving water mass properties due to mixing are investigated for the first time using a high resolution 3D numerical model. An idealized modeling approach forced by a typical annual cycle of buoyancy forcing due to ice production is chosen in a terrain-following vertical co-ordinate. Comparison with observational data, including hydrography, fine resolution current measurements and direct turbulence measurements using a microstructure profiler, gives confidence on the model performance. The model eddy diffusivity profiles contrasted to those inferred from the turbulence measurements give confidence on the skill of the Mellor Yamada scheme in representing sub-grid scale mixing for the Storfjorden overflow, and probably for gravity current modeling, in general. The Storfjorden overflow is characterized by low Froude number dynamics except at the shelf break where the plume narrows, accelerates with speed reaching $0.6 \mathrm{~m} \mathrm{~s}^{-1}$, yielding local Froude number in excess of unity. The volume flux of the plume increases by five-fold from the sill to downstream of the shelf-break. Rotational hydraulic control is not applicable for transport estimates at the sill using upstream basin information. To the leading order, geostrophy establishes the lateral slope of the plume interface at the sill. This allows for a transport estimate that is consistent with the model results by evaluating a weir relation at the sill.
\end{abstract}

Correspondence to: I. Fer

(ilker.fer@gfi.uib.no)

\section{Introduction}

Fluxes through the air-sea boundary lead to evaporation or cooling and, if intense enough, sea ice freezing that may lead to formation of dense waters in the marginal seas or over high-latitude continental shelves. Driven by their density excess relative to the ambient, dense waters flow over topographic features, such as sills and straits (overflow hereafter), and descend the continental slope under the influence of pressure-gradient, Coriolis and frictional forces (Griffiths, 1986). Overflows are bottom-intensified currents and are typically associated with enhanced dissipation and mixing. The amount of mixing an overflow encounters along its path is largely due to entrainment of ambient water and will determine the depth of penetration of the overflow plume. For instance, dense waters formed as a result of ice-freezing over circum-Arctic shelves, depending on the entrainment rate and source water properties, can contribute to the Arctic cold halocline (Aagaard et al., 1981) or penetrate deeper below the Atlantic Water (AW) contributing to the intermediate or deep water masses, thereby ventilating the Arctic Ocean (Rudels and Quadfasel, 1991). The Greenland-Scotland Ridge overflows and high-salinity shelf waters descending shelves of Antarctica are modified by entrainment to produce the North Atlantic Deep Water (Dickson and Brown, 1994) and Antarctic Bottom Water (Gordon et al., 1998), respectively. These deep waters contribute to the global thermohaline circulation and the latter ventilates the deepest ocean. Dynamics of dense fluid descending an inclined boundary have been extensively studied and the oceanographic context is reviewed by e.g. Price and Baringer (1994) and Baines and Condie (1998). Because the ocean general circulation models cannot resolve the detailed overflow dynamics, an accurate representation of entrainment and mixing of overflows is crucial. The sensitivity of overflow simulations to models of

Published by Copernicus Publications on behalf of the European Geosciences Union. 
(a)

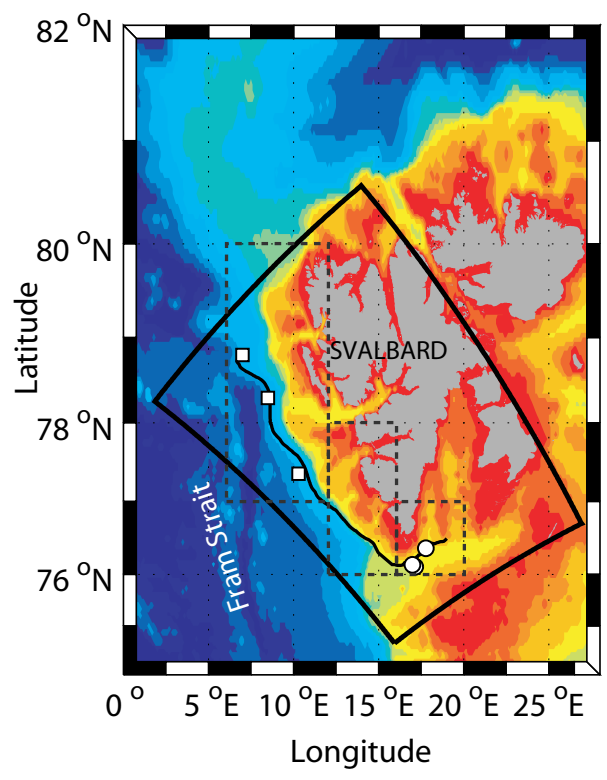

(b)

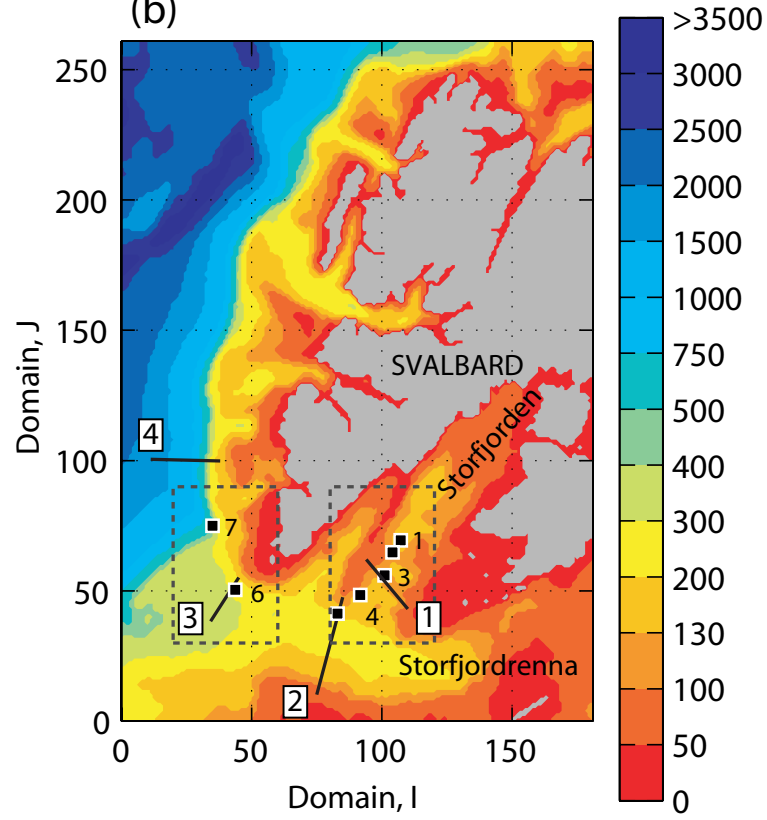

Fig. 1. (a) Map showing the bathymetry (color) around Svalbard together with the model domain (bordered in black) shown in (b), the path of the Storfjorden overflow inferred from a constant descent rate model (Killworth, 2001; black trace) and locations where Storfjorden water were observed (Quadfasel et al., 1988, squares; Fer et al., 2003, circles). The dashed rectangles mark the three regions from which the ambient CTD profile is constructed. (b) The model domain together with stations (black squares marked from 1 to 7 ) and sections (lines marked with white rectangles from 1 to 4). The two dashed rectangles mark the regions shown in Fig. 3. The bathymetries in (a) and (b) are identical with color bar given on the right in units of metre. Section 1 is roughly aligned with the Storfjorden sill. Station 3 is positioned at the sill, at the side where the main overflow occurs.

different type and resolution, and covering a range of physical regimes is recently reported in Legg et al. (2006) with focus on entrainment and mixing. In addition to the bottom drag and entrainment at the dense plume-ambient interface, the overflow's descent can be affected by the detrainment into the stratified environment (Baines, 2001), the Ekman drainage, the variation of the thermal expansion coefficient with depth (thermobaric effect, Killworth, 1977), or the presence of wave-like instabilities (Fer et al., 2001; Cenedese et al., 2004) or eddies (Lane-Serff and Baines, 1998; Cenedese et al., 2004).

Storfjorden (Fig. 1) in the Svalbard Archipelago is a well documented site with production of dense, brine-enriched shelf water (BSW). Here, BSW is produced through iceformation and subsequent brine rejection in a recurring polynya, at a rate of typically 0.06-0.07 Sverdrup (Sv, $1 \mathrm{~Sv} \equiv 10^{6} \mathrm{~m}^{3} \mathrm{~s}^{-1}$ ) when averaged over the freezing period (Skogseth et al., 2005a). Although the BSW volume flux does not show significant inter-annual variability, the salinity of the water accumulated in the basin behind the $120-\mathrm{m}$ deep sill ranges from 34.8 to a record value of 35.8 observed in April 2002 (Anderson et al., 2004). This shelf-produced water overflows the sill, turns westwards in Storfjordrenna, flows northward along the continental slope and, when its density excess permits, sinks deep into the Fram Strait. Associated with the variability in the source water, the Storfjorden overflow has significant inter-annual variability (Schauer and Fahrbach, 1999; Fer et al., 2003, 2004). BSW is at or near the freezing temperature and salinity is the main factor in determining the density excess of the overflow. Storfjordenderived water was observed at several stations (Fig. 1a) in the deep Fram Strait in 1986 (Quadfasel et al., 1988), and more recently in September 2002 (U. Schauer, 2003, personal communication), consistent with the high salinity reported in April 2002.

A previously published numerical modeling study of the Storfjorden overflow was conducted employing a hydrostatic, reduced-gravity plume model with stagnant ambient water (" $1 \frac{1}{2} 2$ layer model") with a local Richardson number dependent entrainment parameterization (Jungclaus et al., 1995). Jungclaus et al. (1995) used idealized synthetic ambient temperature $(T)$, salinity $(S)$ profiles to match the water mass properties that the plume encounters along its descent and applied steady source conditions by maintaining a $30 \mathrm{~m}$ thick (above the sill level) dense layer with $T=-1.75^{\circ} \mathrm{C}$ and $S=35.3$ during 150 days of the simulation. Recently, Skogseth et al. (2008) ${ }^{1}$ conducted an idealized 3-D numerical simulation using the Bergen Ocean Model, with focus on

\footnotetext{
${ }^{1}$ Skogseth, R., Smedsrud, L. H., Nilsen, F., and Fer, I.: Observations of hydrography and downflow of brine-enriched shelf water in the Storfjorden polynya, Svalbard, J. Geophys. Res., submitted, 2008 .
} 
the fate of the polynya derived water in the Storfjorden basin. Here, we use a 3-D shelf circulation model in an idealized set-up to study the pathway and descent of the Storfjorden overflow plume (downstream of the sill) and its evolving water mass properties due to mixing with the surrounding water masses. In the present work we also compare the model results to observations including hydrography, year-long current profile measurements at the sill as well as microstructure measurements and inferred diapycnal eddy diffusivity. The structure of the paper is as follows. The numerical model and the modeling approach (Sect. 2) and the experimental set-up (Sect. 3) are outlined with a description of the domain, ambient conditions and the forcing. Salient features of the model overflow are outlined in Sect. 4. Data extracted at selected sections and stations are compared with the available observations (Sect. 5). Evolution of the plume is presented in Sect. 6. Subsequently, discussion is given on plume and interface characteristics, entrainment and rotating hydraulics.

\section{Approach and the numerical model}

An idealized modeling approach is chosen in a terrainfollowing vertical co-ordinate which concentrates the vertical resolution near the bottom boundary - suitable for overflow modeling. The buoyancy forcing, a typical annual cycle of BSW production in the absence of any other external forcing, is artificially introduced (Sect. 3) into the basin north of the sill and we concentrate on the overflow of the dense plume and its descent deep into the Fram Strait. We employ the Regional Ocean Modeling System (ROMS, Shchepetkin and McWilliams, 2005) based on the primitive Boussinesq equations, terrain-following coordinate system in the vertical (Song and Haidvogel, 1994) and general orthogonal curvilinear coordinates in the horizontal. Pressure-gradient errors at steep topography are reduced by improved schemes (Ezer et al., 2002; Shchepetkin and McWilliams, 2003). The model uses relatively high order explicit finite differences methods with a time splitting between the fast 2-D barotropic mode and the slower baroclinic 3-D mode. In this study, the turbulence closure is Mellor-Yamada level 21/2 with background mixing levels set to $10^{-5} \mathrm{~m}^{2} \mathrm{~s}^{-1}$ for momentum, and $10^{-6} \mathrm{~m}^{2} \mathrm{~s}^{-1}$ for heat and salinity. The model employs a nonlinear equation of state for seawater, hence thermobaric effects are implicitly included. In order to remove mesoscale variability and to delineate the robust and representative features, we average the 5-min model spatial fields over 10 days centered at monthly intervals (day 30 averaged over day 2535 , day 60 averaged over day 55-65 and so on). Section data are stored as 5-day averages (the model step is $5 \mathrm{~min}$ ). Station data are daily snapshots derived from the ROMS daily history files.

\section{Experimental set-up}

\subsection{Domain}

The model domain covers Storfjorden, Storfjordrenna and the continental slope west of Spitsbergen (Fig. 1b). In order to minimize the pressure gradient errors associated with abrupt topography changes, the bathymetry is derived by smoothing ETOPO2 (2001) and interpolating to the grid resolution. We employ 30 vertical layers and an eddy-resolving horizontal resolution of approximately $2 \mathrm{~km}$. Near-bottom vertical resolution, averaged over the deepest five layers, is $4.5 \mathrm{~m}, 11 \mathrm{~m}$ and $22 \mathrm{~m}$ for the water depths of $200 \mathrm{~m}, 500 \mathrm{~m}$, and $1000 \mathrm{~m}$, respectively.

\subsection{Ambient and initial conditions}

The initial density structure is at rest and uniform horizontally. An ambient profile representative of the water masses the plume encounters along its path is constructed using $1^{\circ}$ resolution seasonal hydrography from objective analysis of the World Ocean Atlas 2001 (Conkright et al., 2002). Mean profiles are calculated for three regions, covering increasing along-path distance from the sill, for seasons when the plume is expected to reach the given region. The three regions are indicated in Fig. 1a as dashed rectangles where the bounding south-west and north-east corners are $16^{\circ} \mathrm{E}$ $76^{\circ} \mathrm{N}-20^{\circ} \mathrm{E} 77^{\circ} \mathrm{N}$ for January-March; $12^{\circ} \mathrm{E} 76^{\circ} \mathrm{N}-16^{\circ} \mathrm{E}$ $78^{\circ} \mathrm{N}$ for April-June; and $6^{\circ} \mathrm{E} 77^{\circ} \mathrm{N}-12^{\circ} \mathrm{E} 80^{\circ} \mathrm{N}$ for JulySeptember. The latter period is when the plume has propagated deep in to the Fram Strait, therefore stations with depth less than $500 \mathrm{~m}$ are discarded in the averaging. Finally, a composite profile is constructed at standard depths using the upper $250 \mathrm{~m}$ from January-March, between 400$900 \mathrm{~m}$ from April-June and for depth greater than $1000 \mathrm{~m}$ from July-September. Averaged potential temperature $\theta$, and $S$ profiles are further smoothed using a 5 data point running mean. The resulting ambient profile (Fig. 2) is implemented in the model by linear interpolation to the model levels. In order to approximate the remaining BSW from the previous year, trapped behind the sill, Storfjorden is filled up to the sill depth with dense water of $S=35.2$ and $T=-0.7^{\circ} \mathrm{C}$, derived from observations prior to freezing period (Fer et al., 2004; Skogseth et al., 2005b).

\subsection{Forcing}

The only forcing is the buoyancy forcing as a result of the brine production. This is implemented using the "river mechanism" in ROMS. Dense water with salinity $S=35.3$ and temperature $T=-1.9^{\circ} \mathrm{C}$ is introduced at chosen land/sea interface locations north of the sill. The brine mixes and dilutes before reaching the sill from the discharge locations in the basin (see Sect. 6.2). The source regions are not representative of the Storfjorden polynya. Polynya dynamics, dense water production and its descent, mixing and filling 


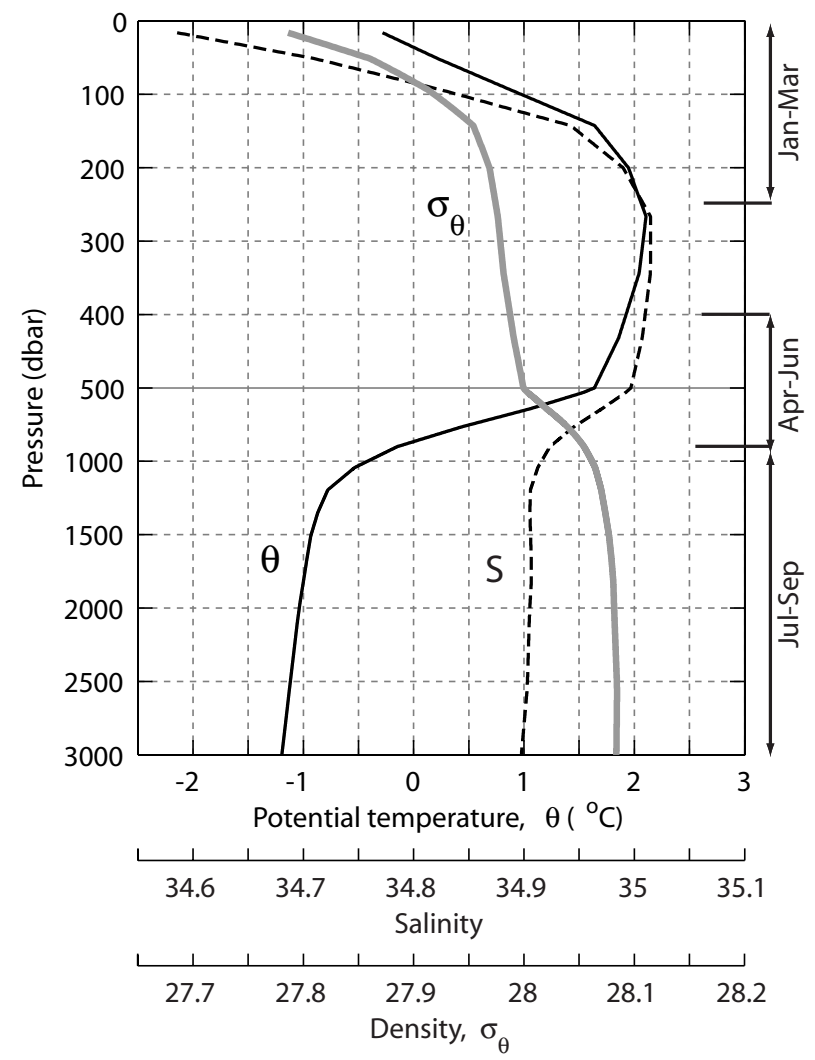

Fig. 2. The idealized ambient CTD profile implemented in the model. Shown profiles are the potential temperature $(\theta$, black solid), salinity $(S$, dashed) and potential density anomaly referenced to surface pressure $\left(\sigma_{\theta}\right.$, gray). Note the change in vertical scale at 500 dbar pressure. The depth ranges for different seasons used in the formulation of the ambient profile are marked on the right.

of the basin are not the focus of this study. In prescribing the brine forcing we rely on results from a wind-driven polynya width model (Haarpaintner et al., 2001; Skogseth et al., 2004) which provides estimates of ice and BSW production using satellite images and wind data together with limited information of surface hydrography. Results from five winters 1998-2002 (Skogseth et al., 2005a) suggest a relatively constant BSW volume flux of 0.06-0.07 Sv throughout the freezing period of typically mid-November to mid-May (about 180 days). Accordingly, we apply the following forcing: The time evolution of the brine supply increases from zero at time $t=0$ to $0.1 \mathrm{~Sv}$ at $t=15$ day, remains constant until $t=90$ day and declines to zero at day 180 . The duration and evolution of the forcing is representative of the freezing period. Averaged over 180 days, $0.07 \mathrm{~Sv}$ of BSW is supplied into Storfjorden. The simulation continues for another 180 days without any external forcing. Early spring hydrography in the deepest layers behind the sill in Storfjorden is reviewed in Skogseth et al. (2005b) and our choice of $S=35.3$ and $T=-1.9^{\circ} \mathrm{C}$ represents a season with moderate dense water production.
In a more realistic setting, the density structure of the ambient water will depend on the inflow of Atlantic and Arctic water masses across the open boundaries which could drive tides and the barotropic flow along the slope west of Spitsbergen. Owing to the idealized forcing employed in this study, the West Spitsbergen Current and the mean circulation in Storfjordrenna are absent, as are the effects of tides and winds. Furthermore, the ambient circulation at the sill is not captured and the density of the winter-cooled water originating the plume is prescribed.

\subsection{Passive tracer}

The water mass behind and below the sill level at $t=0$ $\left(S=35.2\right.$ and $T=-0.7^{\circ} \mathrm{C}$ ) is marked with a passive tracer (TR0) of concentration equal to unity. The source waters supplied during the first 90 days (initial adjustment and the steady forcing period) and between days 90 and 180 (declining phase) are marked with passive tracers $T R 1$ and $T R 2$, respectively, each with unit concentration. The introduction of tracers yields a more confident estimate of the plume thickness at a given station or the plume cross-sectional area for a given section, hence more accurate transport calculations. Using separate tracers for the initial water mass and the source water associated with the different phases of the forcing provides information on the transport and fate of the BSW remnants from the previous winter and of the overflow during active freezing period and spring.

\section{Model overflow: an overview}

With the onset of buoyancy forcing, the initial water mass trapped behind the sill starts spilling over the sill. The plume reaches the shelf-break, out of Storfjordrenna, by day 60 and overflow water with high tracer concentration is trapped in depressions in Storfjordrenna. After the termination of forcing, the plume does not encounter significant descent but spreads laterally and the bottom water in Storfjordrenna is largely diluted. A fraction of the plume water at the sill escapes to the trench between the sill and Spitsbergen. This is further illustrated at a detailed plot of the sill region at day 150 (Fig. 3a). Typical cross-sill velocity of the plume is $10-20 \mathrm{~cm} \mathrm{~s}^{-1}$, consistent with past observations at the site. When the plume reaches the shelf break, it significantly accelerates to about $0.5 \mathrm{~m} \mathrm{~s}^{-1}$ and abruptly descends from $300 \mathrm{~m}$ to $1000 \mathrm{~m}$ isobath (Fig. 3b). Daily time series at the sill station have considerable variability of the thickness and speed of the plume, suggesting pulsing events (not shown), possibly due to Kelvin-wave-like traveling disturbances in the basin. The water depth at the sill is about $120 \mathrm{~m}$, and occasionally the plume covers the whole depth. Here and in the following the plume thickness, $h_{\text {plume }}$, is estimated as the height above the bottom where the total tracer concentration 
a)

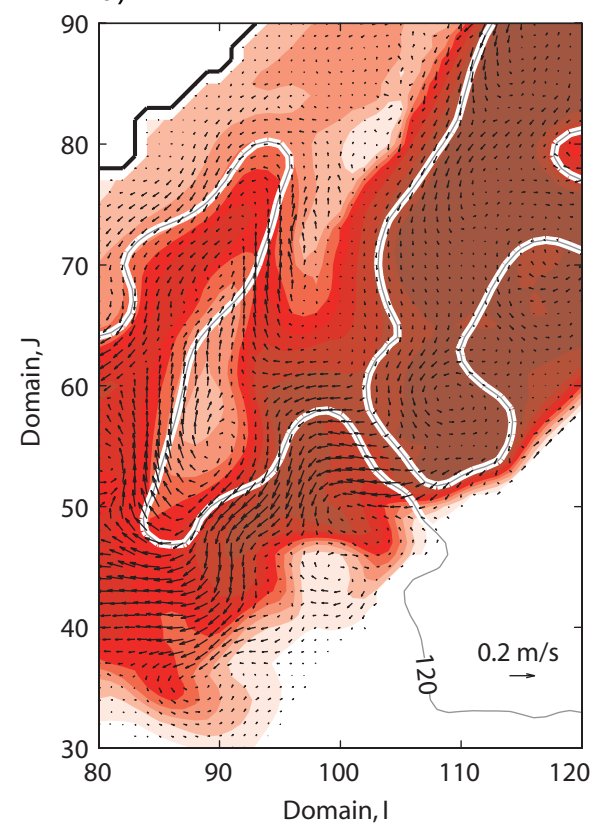

b)

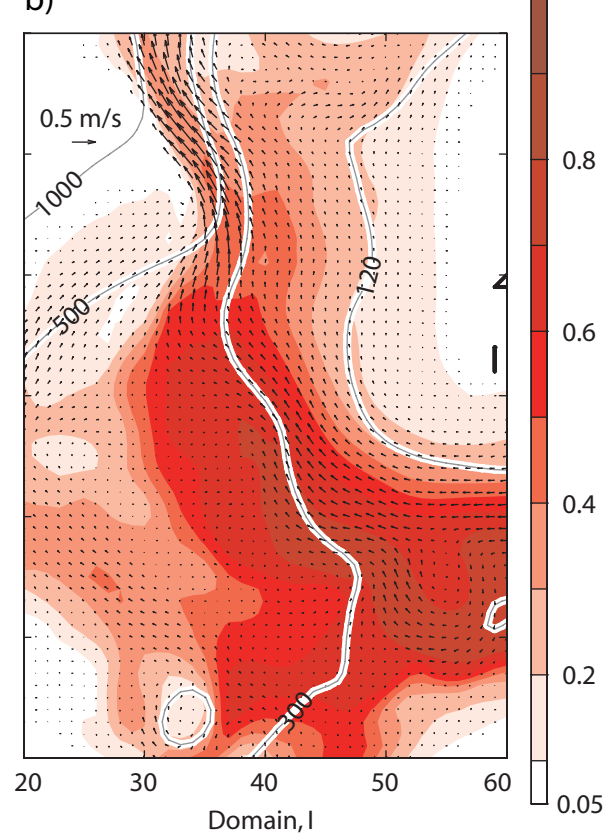

Fig. 3. Total tracer concentration (color) and velocity vectors for the bottom-most layer at day 150, shown in detail (a) in the vicinity of the sill and (b) close to the shelf-break at the mouth of Storfjordrenna. The location of each panel is identified on the regional map in Fig. 1b. Note the different scale of the velocity vector $\left(0.2 \mathrm{~m} \mathrm{~s}^{-1}\right.$ in a and $0.5 \mathrm{~m} \mathrm{~s}^{-1}$ in b). White enveloped gray traces are isobaths in meter. Only data with $T R>0.05$ are shown.

$(T R=T R 0+T R 1+T R 2)$ first falls below $0.05^{2}$. The velocity component along the mean flow is typically about $10 \mathrm{~cm} \mathrm{~s}^{-1}$ and reaches $25 \mathrm{~cm} \mathrm{~s}^{-1}$, correlated with high bottom salinities. The source water marked at the steady-forcing phase $(T R 1)$ and the declining phase (TR2) reaches the shelf-break at about day 60 and day 150, respectively, about 45 days and 60 days after their initiation. The source water concentration in the plume is strongly reduced from the sill to the shelf break. At day 150, the plume has descended deep into the Fram Strait down to $\sim 2000 \mathrm{~m}$ isobath and approached the northern boundary of the domain.

\section{Comparison with observations}

\subsection{Hydrography}

In the absence of an ice-going vessel, surveys of the Storfjorden overflow are typically conducted in Storfjordrenna in spring or in summer, corresponding to periods with declining or terminated brine production. The summertime hydrographic properties of the water column are significantly different than the idealized ambient profile implemented in

\footnotetext{
${ }^{2}$ The plume thickness is sensitive to the choice of concentration threshold, especially in deep water where the dense plume is capped by thick but highly diluted source water. However, because the velocity of such mixed water is very low, the volume transport is not very sensitive to this choice.
}

the simulation and differ further due to the mean circulation of the modified-Atlantic water and due to the presence of the Polar Front (Skogseth et al., 2005b). Keeping these caveats in mind we compare the model results with observations conducted in 2002. Section 2 across Storfjordrenna and Sect. 3 extending southwards from the southern cape of Spitsbergen are chosen to match the sections worked in $\mathrm{Au}-$ gust 2002 (Fer et al., 2004) and in May 2002 (Skogseth et al., 2005b), respectively. Temperature and salinity distribution at model days 192.5 (representative of early summer) and 87.5 (representative of spring) are presented in Figs. 4 and 5 together with the observations. The freezing period of 2002 resulted in record high salinity in the basin (Anderson et al., 2004) which is not consistent with the moderate forcing of the simulation. The observed overflow plume is therefore more saline at both sections. Nevertheless, the salient features of the bottom temperature-salinity structure are captured by the model. In the absence of passive tracer, $\sigma_{\theta}=28.0$ is a good indicator of the extent and thickness of the overflow plume at the observation sites and is also similar to the $T R=0.05$ isoline for the model. In Storfjordrenna (model Sect. 2), the model plume extends shallower towards Spitsbergen, to depths shallower than the sill depth, whereas the shallow edge of the observed plume is at approximately the sill depth (Fig. 4). Because the model ambient for this region is from early spring climatology, when the plume is first expected to reach this site, the summer ambient differs 

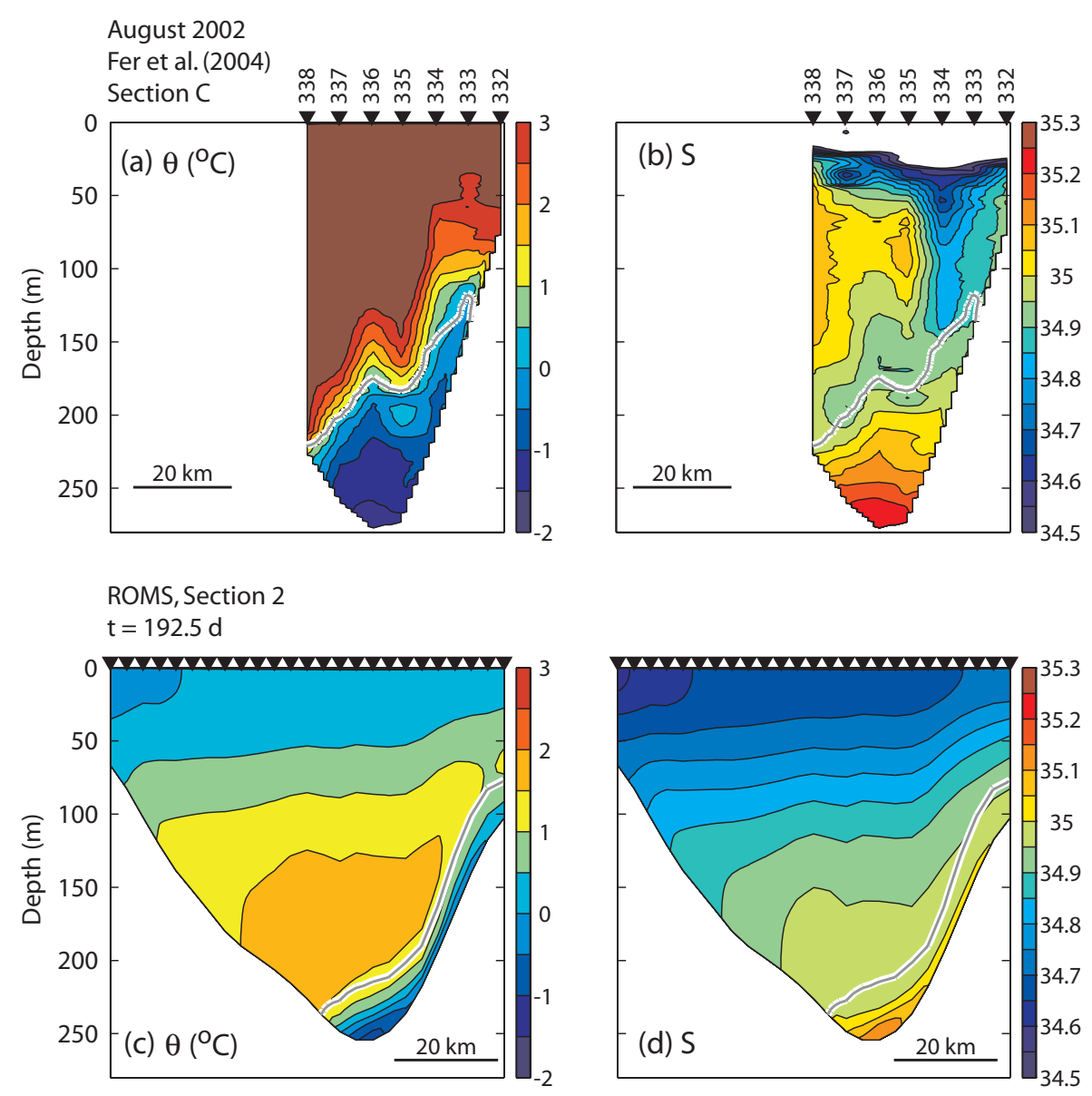

Fig. 4. Potential temperature, $\theta$, and salinity, $S$ distributions from (a-b) observations in August 2002, section C of Fer et al. (2004) and (c-d) Sect. 2 of this study at day 192.5. Sections are approximately at the same location and are roughly aligned to ease comparison. Sampling locations are marked by triangles above each panel including station numbers of CTD observations. White-enveloped gray isoline is $\sigma_{\theta}=28.0$ in all panels.

significantly from the model. The doming of the isotherms and shown $\sigma_{\theta}=28.0$ isopycnal in Fig. $4 \mathrm{a}$ are a result of the mean cyclonic circulation of the West Spitsbergen Current in Storfjordrenna which is absent in the model forcing. At Sect. 3 the model plume on the slope is thicker (Fig. 5) than the observed plume, the mixing of which is suppressed by relatively strong stratification. This is possibly due to enhanced shear at the plume-ambient interface and resulting mixing imposed by the Mellor-Yamada closure. The overflow water in the observed plume is wider, extending over the whole section on the flat bottom, suggesting that the bottom friction and resulting Ekman drainage feeding the quiescent deep part of the section are not properly represented in the model.

\subsection{Current at the sill}

In 2004, a self-contained upward-looking $307.2 \mathrm{KHz}$ broadband Workhorse, RD Instruments acoustic Doppler current profiler (ADCP) was deployed at the sill averaging 33 pings per ensemble every $10 \mathrm{~min}$ at $4 \mathrm{~m}$ vertical bins. The first bin was centered at about $6 \mathrm{~m}$ above the bottom and temperature was also recorded by a sensor on the ADCP (about $0.5 \mathrm{~m}$ above the bottom). As judged from the temperature near the freezing point and persistent cross-sill velocity directed out of the fjord (except for a reversal around day 70), the overflow was observed between days 60 to 210 of 2004 (Fig. 6). We compare the observed bottom current to the data extracted at model station 3 (sill) at the third layer $6 \mathrm{~m}$ hab, consistent with the bottom-most ADCP bin (Fig. 6, model time is aligned with the ADCP time to match the development of overflow temperature at freezing point). The ADCP record comprises signatures of the mean circulation, effect of tides (although the record is 5-days low-passed), and the response to wind forcing, none of which were incorporated in the simulation. Nonetheless, both the magnitude and the variability of the cross-sill current are comparable to the observations. The common time frame, indicated by arrows in Fig. 6a, is further compared in Fig. 7 by presenting the 

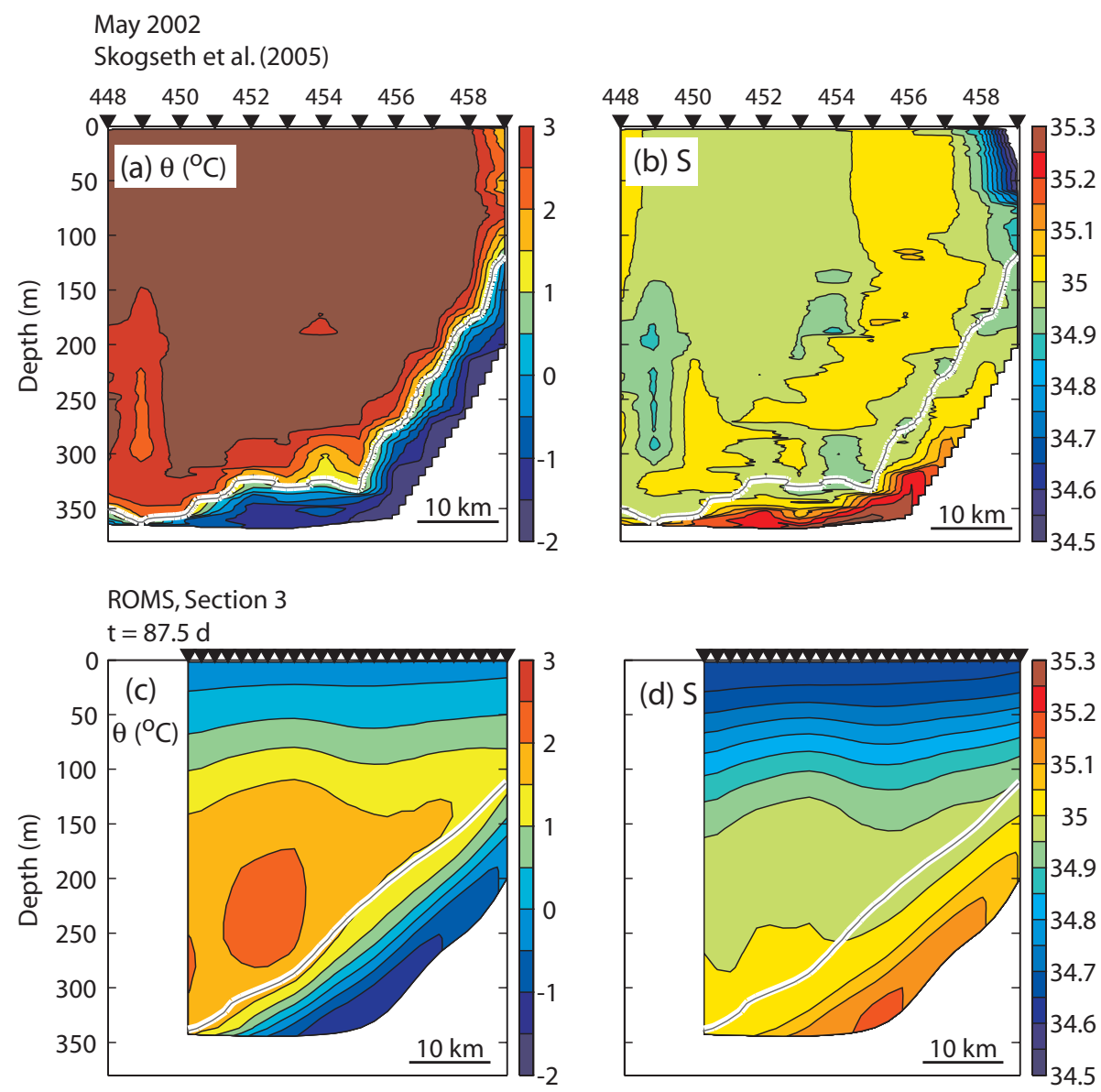

Fig. 5. Same as Fig. 4 but for observations in May 2002 (Skogseth et al., 2005b), and Sect. 3 of this study at day 87.5.

progressive vector diagrams at $6 \mathrm{~m}$ hab and the mean profiles over the ensembles when the bottom temperatures were less than $-1.5^{\circ} \mathrm{C}$ (i.e. cold overflow periods). Over about 7 months, the integrated cross-sill displacement from the model is in good agreement with the data. The along-sill distance covered by the plume at the sill is comparable to the $\mathrm{ADCP}$ record at the second half of the period. At times of cold bottom temperature, the mean profile of the cross-sill component of the velocity differs between the model and the ADCP data: the observed current profile is directed out of the fjord over the resolved depth range and is relative weak in the bottom $30 \mathrm{~m}$, whereas the model profile has a well-defined plume velocity signature. The profiles of the along-sill component, on the other hand, are in remarkable agreement in the bottom $30 \mathrm{~m}$. At shallower depths, the ambient circulation at the sill is not captured by the model owing to the idealized forcing.

\subsection{Eddy diffusivity}

Profiles of dissipation of turbulent kinetic energy per unit mass, $\varepsilon$, were collected in August 2005 from R. V. Håkon
Mosby using a loosely-tethered microstructure profiler equipped with two shear probes. Details of the instrument, typical deployment, and data processing are described in Fer (2006) for a similar survey. Diapycnal eddy diffusivity is inferred from the measured $\varepsilon$ and the background stratification using $K_{\rho}=0.2 \varepsilon N^{-2}$ (Osborn, 1980), where $N$ is the buoyancy frequency. Profiles are available in the vicinity of station 1 in the basin, station 3 at the sill, station 4 and 5, 25 and $50 \mathrm{~km}$ downstream of the sill, respectively. Observed profiles of $\mathrm{K}_{\rho}$ with respect to distance above the sea bottom are compared to vertical eddy diffusivity profiles extracted from the model at the corresponding stations (Fig. 8). The model diffusivity changes smoothly in time and we present profiles averaged in 14-day windows centered at $t=75,100$ and 150 day. Day 150 is representative of the summer observations. In the basin, the model diffusivity in the ambient and within the dense water behind the sill does not show significant temporal variability and is comparable with the measured profile. Both at the sill and at the stations downstream from the sill, the diffusivity is enhanced close to the bottom, as expected from bottom-attached gravity currents. At the sill, the model diffusivity in the bottom $15 \mathrm{~m}$ decreases through time 

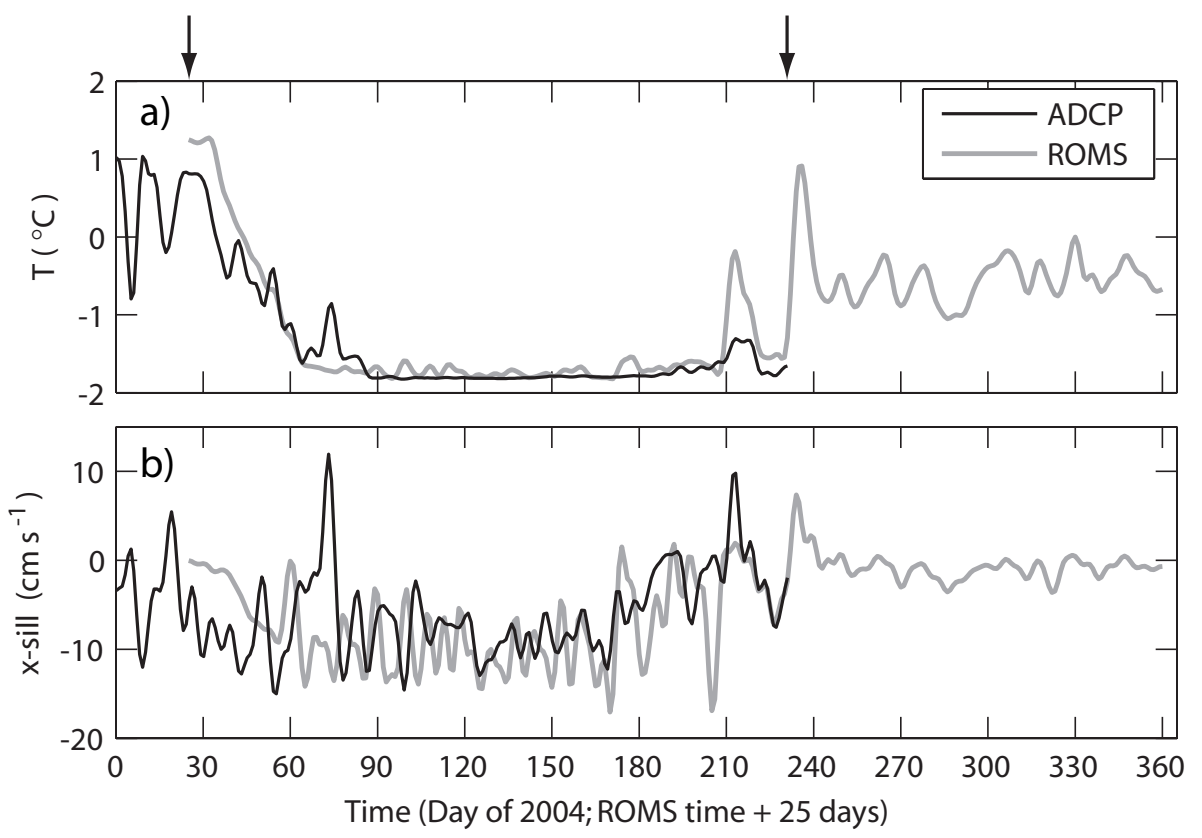

Fig. 6. Time series of (a) bottom temperature (b) cross-sill component of the velocity recorded by an upward-looking ADCP deployed at the sill in 2004 (black) and that extracted at the model station 3 (gray). Simulation time is shifted by 25 days to align with the observed overflow period in 2004, judged from the bottom temperatures near the freezing point. The two arrows mark the common time frame compared in Fig. 7. Both data sets are daily averaged (ADCP sampling rate is $10 \mathrm{~min}$ ) and 5 days low-passed.

in response to weakening in buoyancy forcing and the resulting shear. The bottom signature at day 150 is in excellent agreement with the observed profile. Farther downstream mixing within the plume is also comparable at day 150. Relatively large diffusivity in the model compared to the observations $25 \mathrm{~km}$ downstream between $10-25 \mathrm{~m}$ height above bottom (hab) is an example of the structure that could lead to relatively thick and diluted interface layer in the model (compare Fig. 5a-b and Fig. 5c-d). Farther above the interface, the mixing in the ambient is typically underestimated in the model, owing to lack of processes leading to relatively large diffusivity in the ambient imposed by the circulation, wind and internal waves (Fer, 2006). However, note that the model stratification in the ambient, as a consequence of the implemented hydrography (Fig. 2), is different from the summer conditions which will also affect the diffusivity estimates through the $N^{2}$ dependence in the Osborn model. Comparison with the observed $K_{\rho}$ profiles gives some confidence on the skill of the Mellor-Yamada scheme in representing sub-grid scale mixing for gravity current simulations. In support of this result, Ezer (2005) reported that in both $2.5 \mathrm{~km}$ and $10 \mathrm{~km}$ resolution terrain-following coordinate model, the Mellor-Yamada scheme represented the subgrid scale mixing very well compared with $0.5 \mathrm{~km}$ resolution non-hydrostatic model results.

\section{Pathway, descent and evolution of the plume}

\subsection{Core properties}

In this section plume properties are presented for the core stations along the path of the plume. Properties for the crosssections along the path are given in the next section. The core of the plume is derived using 10-day averaged fields available every 30 days. The core is detected as the grid with the highest total passive tracer concentration along $I$-slices between $I=50$ to 100 and along $J$-slices (after masking Storfjorden and Storfjordrenna) for $J>60$, where $I$ and $J$ are the two horizontal grid indices of the domain, respectively (see Fig. 1). Several quiescent deep pools in Storfjordrenna eventually trap the densest waters and are not representative of the dynamic path of the plume (Fer et al., 2003). We therefore masked several such depressions after verifying that the along path component of the velocity is not elevated as would be expected from an active plume but is rather quiescent. Once the path of the overflow is established by joining the core stations, its orientation for each station is derived after smoothing by 10 point $(\approx 20 \mathrm{~km})$ moving average. Using the smooth path orientation, the model horizontal velocity components are aligned with the path direction. The thickness of the plume, $h_{\text {plume }}$, is estimated to be the height above bottom (hab) where $T R$ first falls below 0.05 . Along path distance is estimated by integrating the great-circle distance between the neighboring core stations. The along-path and temporal 

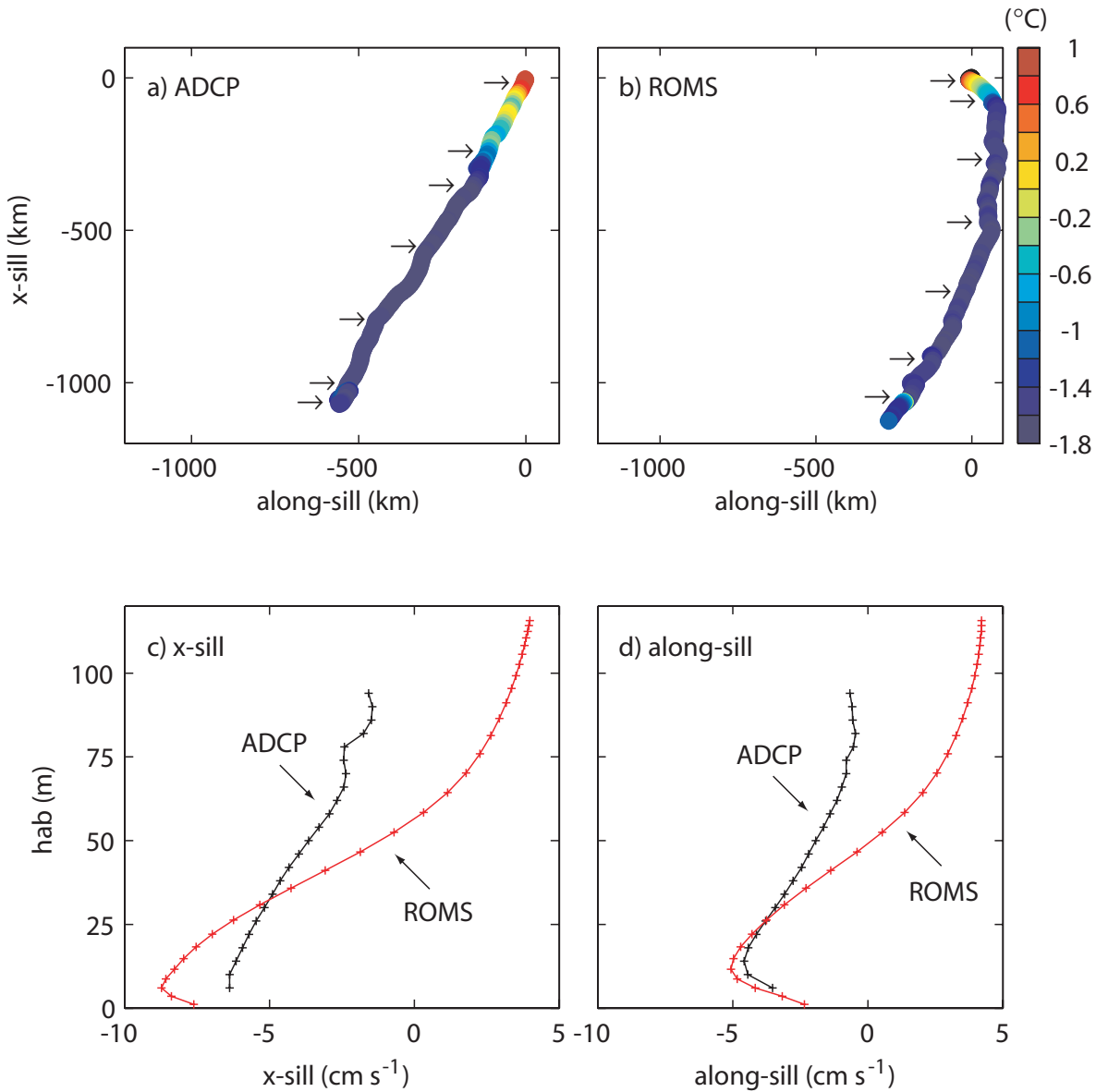

Fig. 7. Progressive vector diagrams at $6 \mathrm{~m}$ hab at the sill derived from (a) ADCP observations and (b) model results. The color code is for the bottom temperature and arrows are placed at 30 day intervals. Vertical profiles of (c) cross-sill (positive towards the fjord) and (d) along-sill component (positive approximately towards east) of the time averaged velocity for observations (black) and model (red) for the times with cold overflow when $T<-1.5^{\circ} \mathrm{C}$. This threshold results in 155 and 150 daily ensembles for ROMS and ADCP, respectively.

evolution of the core is presented in Fig. 9. Figure 9a and $b$ show the time-distance maps of $h_{\text {plume }}$ and maximum alongcore velocity within $h_{\text {plume. }}$. At the shelf-break, between 200 and $250 \mathrm{~km}$ downstream from the sill, the plume accelerates to maximum core velocity reaching $0.6 \mathrm{~m} \mathrm{~s}^{-1}$. The alongpath transect of core velocity with respect to hab at day 150 is shown in Fig. 9c together with plume thickness and two chosen isopycnals. Finally profiles of density excess (difference between $\sigma_{\theta}$ at day 150 and $t=0$ ), along-path component of the velocity and tracer concentration, $T R$ in the bottom $150 \mathrm{~m}$, are presented at selected distances from the sill (Fig. 9d-g). The plume thickness inferred from $T R$ profile using a threshold of 0.05 captures the interface below which density excess and speed increases from the ambient values. At the continental slope and farther downstream the interface between the plume and the ambient is highly diluted, resulting in plume thickness exceeding $300 \mathrm{~m}$, but with low core speed. The core $T-S$ properties at the bottom layer at $t=0$ and $t=150$ day are shown in Fig. 10. Those at $t=0$ correspond to the ambient, as specified by the initial profiles in
Fig. 2, at the appropriate depth of the core along the plume path. The ambient properties at the bottom layer along the plume path encounter Atlantic Water (AW) core and Norwegian Sea Deep Water (NSDW) at about $100 \mathrm{~km}$ and $400 \mathrm{~km}$, respectively, downstream from the sill. At day 150 , the core $T-S$ properties of the plume are modified as a result of entrainment and mixing. The BSW at the sill is a mixture of the dense source water, the prescribed basin water (to the sill level) and the ambient properties above the sill level. This mixing takes place as the source waters propagate from the discharge locations towards the sill. From the sill towards the shelf-break (about $220 \mathrm{~km}$ ), the overflow plume properties trace a mixing line between the diluted source water at the sill and AW. Farther downstream the mixing takes places in a triangle formed by the plume properties at the shelf-break, AW and NSDW (Fig. 10). Because the cold plume entrains relatively warm $\mathrm{AW}$, it appears as heat source for the ambient after about $x \approx 300 \mathrm{~km}$ where it is mainly driven by its salinity excess. 
(a) $\operatorname{Basin}(\mathrm{St} 1)$

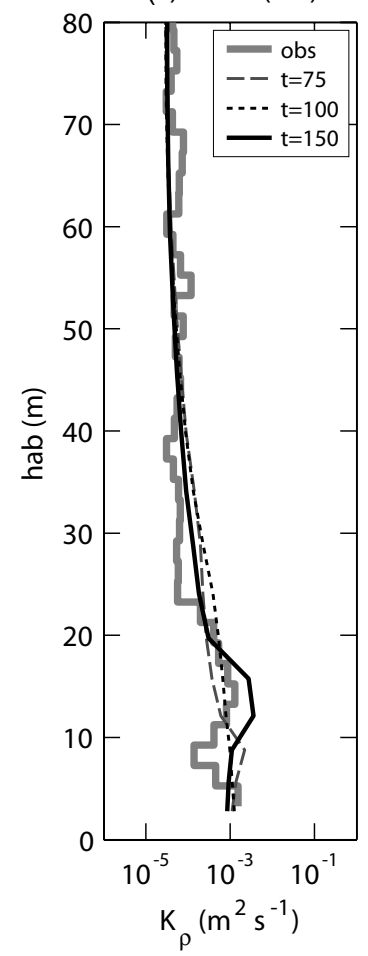

(b) Sill (St3)

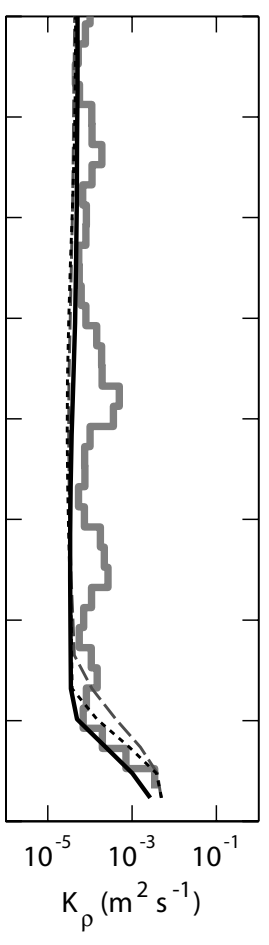

(c) $\mathrm{x}=25 \mathrm{~km}(\mathrm{St} 4)$

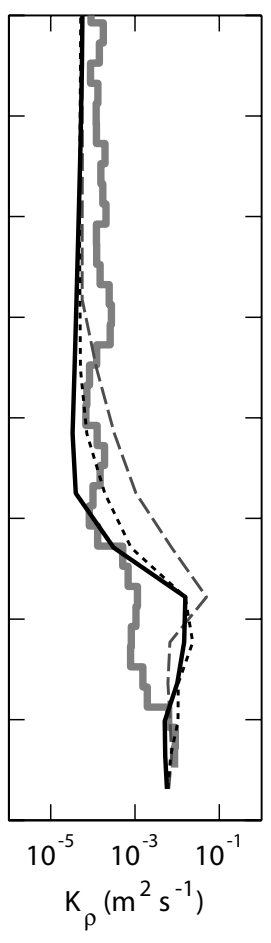

(d) $x=50 \mathrm{~km}(\mathrm{St} 5)$

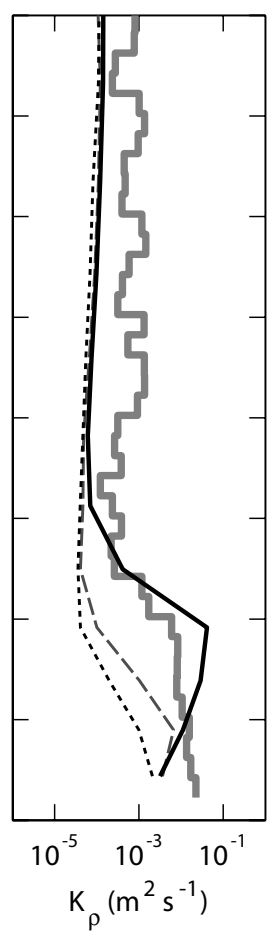

Fig. 8. Vertical profiles of eddy diffusivity $K_{\rho}$ at stations (a) inside Storfjorden, upstream of the sill (Station 1), (b) at the sill (Station 3 ), (c) approximately $25 \mathrm{~km}$ and (d) $50 \mathrm{~km}$ downstream of the sill (stations 4 and 5). Vertical axis is the height above the bottom. Observed $K_{\rho}$ profiles are derived from shear-probe microstructure measurements from a free-fall profiler using the Osborn model (Osborn, 1980) and are averages of typically 5 repeat profiles collected within $0.5 \mathrm{~h}$. Model profiles are two-week averages centered at the indicated times. Observations were made in summer during weak overflow conditions and can be compared to model day 150.

\subsection{Volume transport and entrainment}

The net volume transport of the overflow plume out of Sects. 1 to 4 is calculated as

$Q=\iint_{A} u d z d y$

where $A$ is the plume cross-sectional area bounded by the seafloor and $T R=0.05$ surface, $u$ is the component of velocity out of the section, $z$ and $y$ are the vertical and lateral coordinates, respectively. The volume transport associated with each tracer is calculated by weighting $Q$ with the corresponding concentration

$Q_{T R_{i}}=\iint_{A} u T R_{i} d z d y$

where $i$ runs from 0 to 2 . Total transport of source water is then $Q_{T R}=Q_{T R 0}+Q_{T R 1}+Q_{T R 2}$. Due to entrainment, the overflow volume transport is larger than $Q_{T R}$ and can be quantified by the ratio $R=Q / Q_{T R}$. Figure 11 summarizes the results for the first 300 days of the simulation. Already at the sill section the volume transport is nearly doubled because of both the mixing at the sill and the mixing that the source waters encountered while approaching the sill from their discharge locations in the basin. The increase in volume transport at Sect. 4 is close to $600 \%$ comparable to about $500 \%$ estimate by Quadfasel et al. (1988) and the modeling result of $441 \%$ (standard case) to $678 \%$ (large density anomaly case) by Jungclaus et al. (1995).

Following Legg et al. (2006), we diagnose the entrainment coefficient (ratio of net entrainment velocity and the local current speed) along the path of the plume as

$E(x)=\frac{\frac{d}{d x} Q(x)}{L \bar{u}}$

where $x$ is the along-path distance, $Q$ (Eq. 1) is the overflow transport across a section perpendicular to the path at each core station, $L$ is the lateral extent of the plume on the slope and $\bar{u}$ is the average plume velocity defined by

$\bar{u}=\frac{\iint_{A} u d y d z}{A}$

where $u$ is the along-path component of the velocity and $A$ is the cross-sectional area of the overflow at a given section. In practice, we estimate $L$ as $W \cos (\gamma)^{-1}$ where $\gamma$ is the mean cross-path bottom slope and $W$ is the width of the plume on 

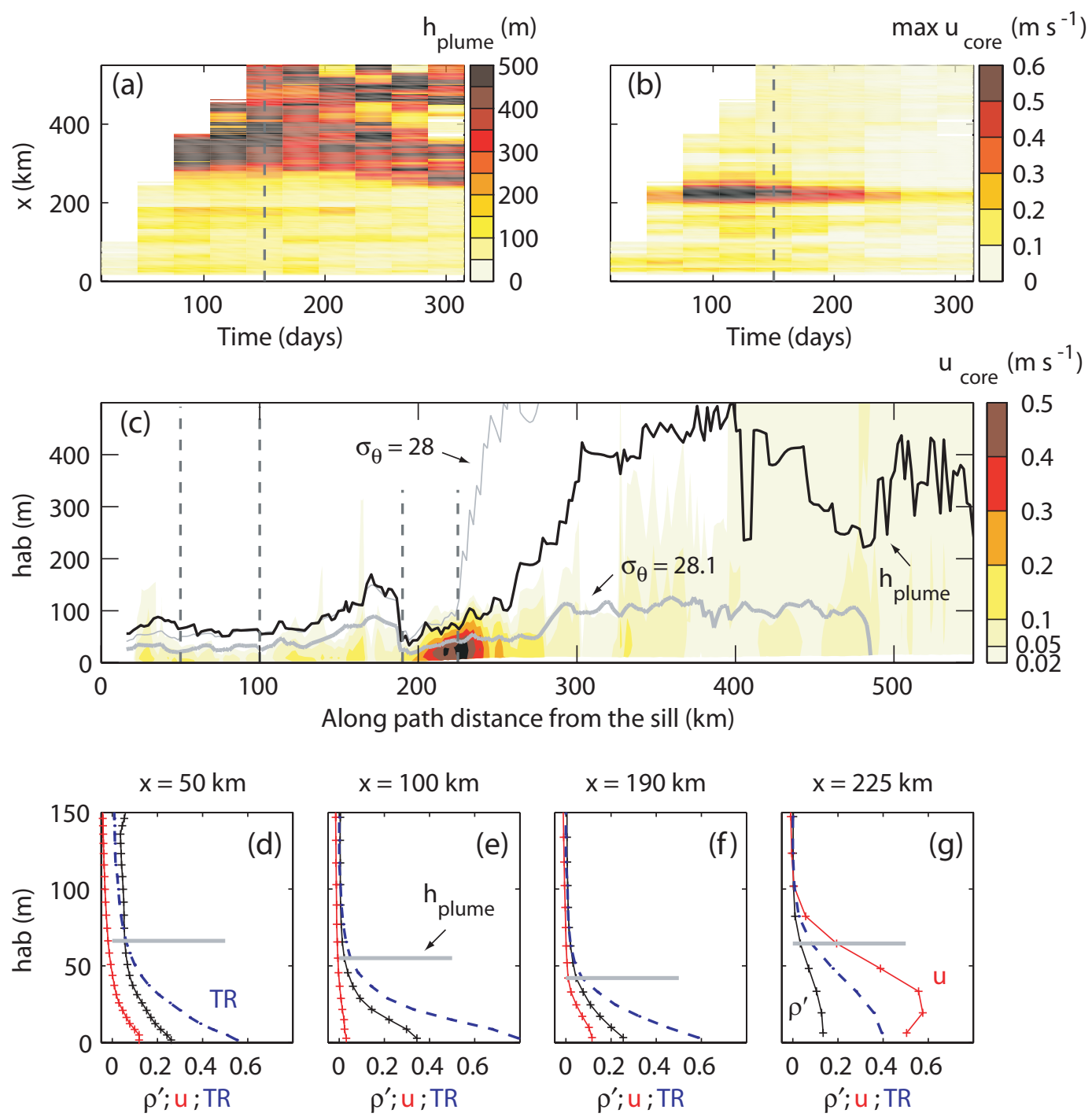

Fig. 9. Time-along path distance evolution of (a) plume height, $h_{\text {plume}}$, and (b) maximum core velocity, $u_{\text {core }}$ Vertical dashed lines mark

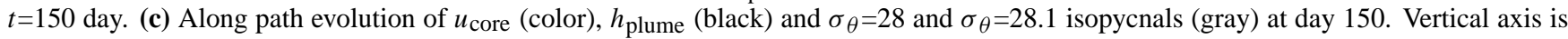
height above bottom (hab) and dashed vertical lines mark $x=50,100,190$ and $225 \mathrm{~km}$ presented in (d-g). Vertical profiles of $u_{\text {core }}($ red), density anomaly $\rho^{\prime}$ (black) and tracer concentration TR (blue dashed) in the bottom $150 \mathrm{~m}$ at (d) $50 \mathrm{~km}($ e) $100 \mathrm{~km}$ (f) $190 \mathrm{~km}$ and (g) $225 \mathrm{~km}$ distance along the path. The plume thickness inferred for each profile is marked by horizontal gray lines.

horizontal $y$-plane. The bottom slope is calculated by slope of the least-squares line fit of bottom depth against horizontal distance. In evaluating Eq. (3), $Q(x)$ is first-differenced over a 10-section moving window along the path, corresponding to $20( \pm 1.5) \mathrm{km}$ ( \pm 1 standard deviation). The resulting entrainment coefficient suggests detrainment (negative $\mathrm{E}$ ) at the trench in Storfjordrenna before the plume reaches the shelf break (Fig. 12e).

Froude number is typically used to infer the dynamical regime of a gravity current plume, as laboratory results suggested good correlation with Froude number above unity and entrainment. Storfjorden overflow is typically associated with low local Froude number $F r^{2}=\Delta u^{2} /\left(g^{\prime} h_{\text {plume }}\right)$, except at the shelf break where Fr slightly exceeds unity (Fig. 12c). Here $g^{\prime}=g \Delta \rho / \rho$ is the reduced-gravity, $\Delta \rho$ is the density excess of the plume relative to the ambient, $\Delta u$ is the difference between the along-path component of the plume velocity and the ambient, and $\Delta u$ and $\Delta \rho$ are calculated as the difference between the averaged properties over $h_{\text {plume }}$ and above. An alternative definition, composite Froude number $G$ for a two-layer system, $G^{2}=F r_{1}^{2}+F r_{2}^{2}$, where $F r_{i}^{2}=u_{i}^{2} /\left(g^{\prime} h_{i}\right)$ is the local Froude number for each layer with thickness $h_{i}$ and speed $u_{i}$, suggests a similar pattern with along path distance (Fig. 12c). On the average $F r=0.25$ and $G=0.2$ using local values at the core. When averaged across the section, $F r$ is typically half the local core value. Daily values of $F r$ derived 


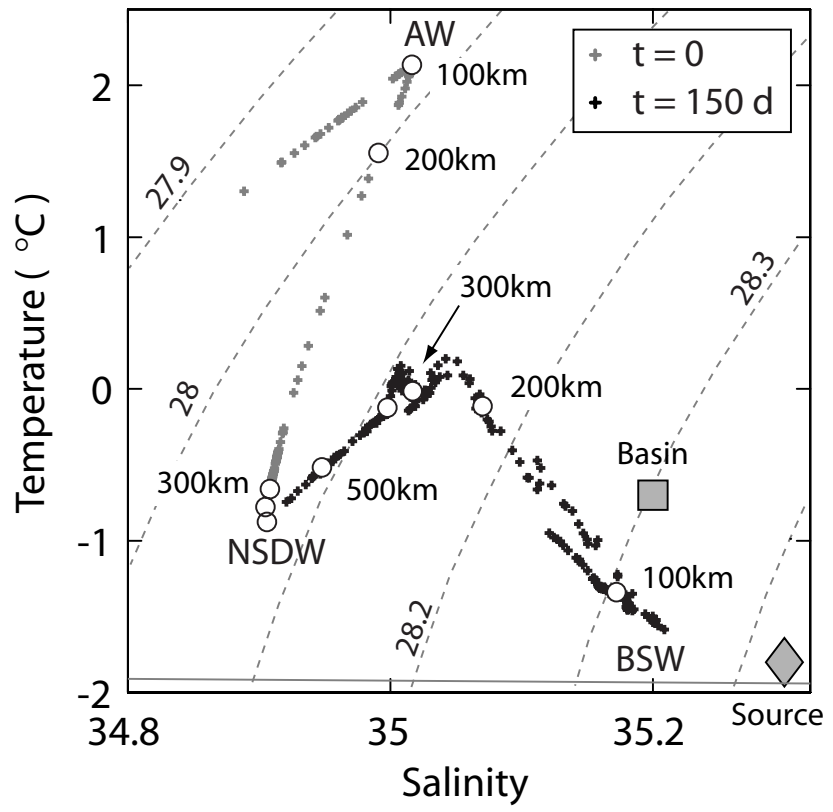

Fig. 10. Bottom temperature-salinity properties at the core along the path of the plume (gray: $t=0$; black: $t=150$ day). Data points for $t=0$ correspond to the ambient, as specified by the initial profiles in Fig. 2, at the appropriate depth of the core along the plume path. White bullets are placed at $100 \mathrm{~km}$ intervals as in Fig. 13 for comparison. Properties of the source water (diamond) and the water in the basin at $t=0$, representative of the condition prior to ice formation (rectangle marked Basin) are also shown. Indicated main water masses are Norwegian Sea Deep Water (NSDW), Atlantic Water (AW) and brine enriched shelf water (BSW). Dashed contours are isopycnals $\left(\sigma_{\theta}\right)$ and the diagonal line at $\approx-1.9^{\circ} \mathrm{C}$ is the freezing temperature at surface pressure.

using the model station data are typically larger than that derived from the 10-day average field (compare squares and the errorbars with the thick black line in Fig. 12c) and the consequences for the entrainment are discussed in Sect. 7.2.

Normalized plume thickness, $h_{\text {plume }} / h_{E}$, is typically large (>10) except near the shelf-break between $210-240 \mathrm{~km}$ from the sill where the plume thickness is about 3-5 times $h_{E}$. Here $h_{E}$ is the Ekman layer thickness, $h_{E}=\left[2 K_{m} /(f\right.$ $\cos (\gamma))]^{1 / 2}, f$ is the Coriolis parameter and $K_{m}$ is the eddy viscosity. Eddy viscosity averaged over $h_{\text {plume }}$ at the core ranges from $3 \times 10^{-5}$ to $2 \times 10^{-2} \mathrm{~m}^{2} \mathrm{~s}^{-1}$, with lowest values at gentle slopes between $70-100 \mathrm{~km}$ and large values between $215-235 \mathrm{~km}$ from the sill.

\section{Discussion}

\subsection{Plume characteristics}

Downstream of the shelf-break the modeled plume is thick and highly diluted. Plume thickness of $200-400 \mathrm{~m}$ is larger than the $10-100 \mathrm{~m}$ thick signature of the Storfjorden water observed in Fram strait (Quadfasel et al., 1988) but it is comparable to the reduced gravity model results of Jungclaus et al. (1995). Both the variability in the overflow and the limitations of the model are likely responsible for the discrepancy between the observations and the model results. Lacking a systematic sensitivity study, we cannot evaluate the role of the variability in the overflow. In the Fram Strait, the plume/ambient interface is highly diluted and the plume thickness is likely overestimated using $T R=0.05$ threshold. Albeit very small, the background mixing level for scalars prescribed in the turbulence closure scheme (Sect. 2) can be significant in diluting the plume. On the other hand, lacking tracer information, plume thickness inferred from observations might be biased low as low source water concentrations will not be immediately obvious in the hydrography. The decreasing vertical resolution as the plume reaches deeper water also hinders an accurate estimate of the plume thickness. The spatial distribution of bottom density anomaly and contours of plume thickness at day 150 are shown in Fig. 13. A fraction of the overflow spills to the trench between Spitsbergen and the sill, consistent with the Bergen Ocean Model simulation of Skogseth et al. (2008) ${ }^{1}$. As a result, thick patches of Storfjorden water, albeit with low density deficit, are found both in the trench between the sill and Spitsbergen, and on the continental shelf west of Spitsbergen. To the authors' knowledge the only observation reported from this trench is in support of the model result: the year-long time-series collected from instruments moored at this trench show indications of cold water with salinity in excess of 34.8 and occasionally reaching 35.2 during April-May 1992 at $36 \mathrm{~m}$ hab (Sternberg et al., 2001). At the mouth of Storfjordrenna where the bottom slope is gentle, the plume accumulates (this is where the detrainment occurs) and is about $150 \mathrm{~m}$ thick before it contracts at the shelf break at about $200 \mathrm{~km}$ downstream from the sill. There is a major difference from the results reported by Jungclaus et al. (1995). Their idealized reduced-gravity simulation of the plume evolves into two branches: the main branch propagating northward into the Fram Strait and a second branch propagating southward along a deep trench east of the Knipovitch Ridge. This is likely an artifact of the 5-min resolution digitized world ocean data set bathymetry employed in Jungclaus et al. (1995) (see the diverging 2000-m isobath near the Knipovitch Ridge in their Fig. 3).

The path of the plume integrated using the model of Killworth (2001) with a constant descent rate of $1 / 400$ compares favorably with the path inferred from the core stations (Fig. 13a). The chosen descent rate underestimates the sinking after the shelf break between 200 and $300 \mathrm{~km}$ but captures the path farther downstream.

The descent and mixing of the overflow plume depend on several factors not taken into account in this study. Wind forcing is generally important in the region. Numerical experiments not reported here show that wind from south into Storfjorden significantly enhances the overflow rate. The 


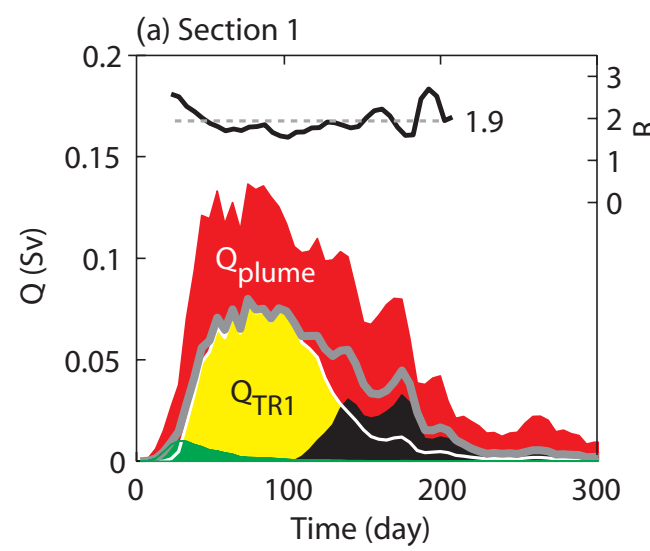

(b) Section 2

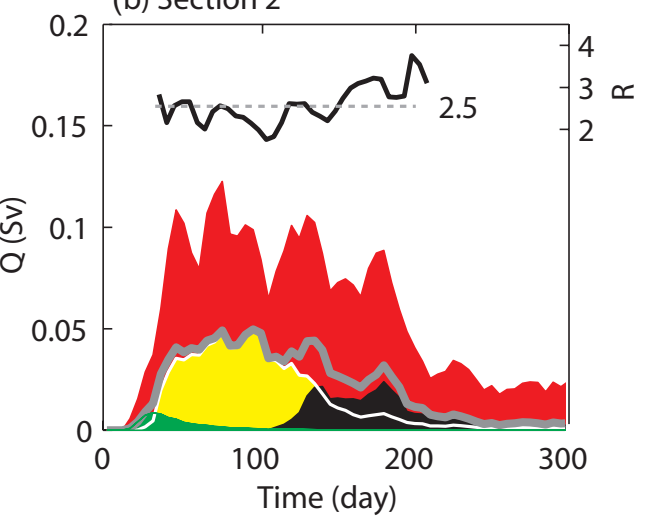

(c) Section 3

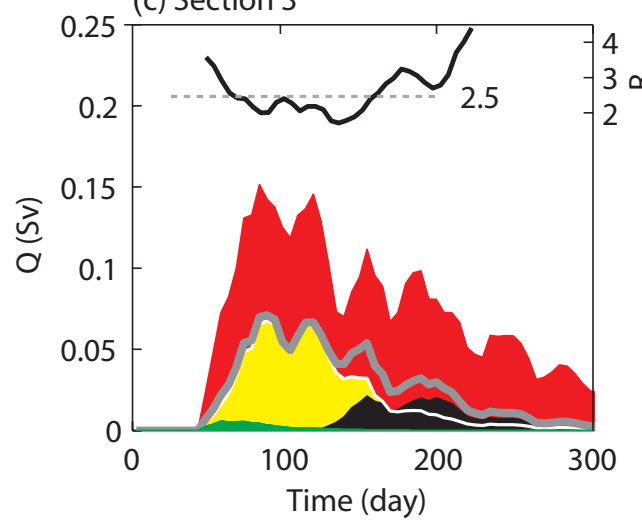

(d) Section 4

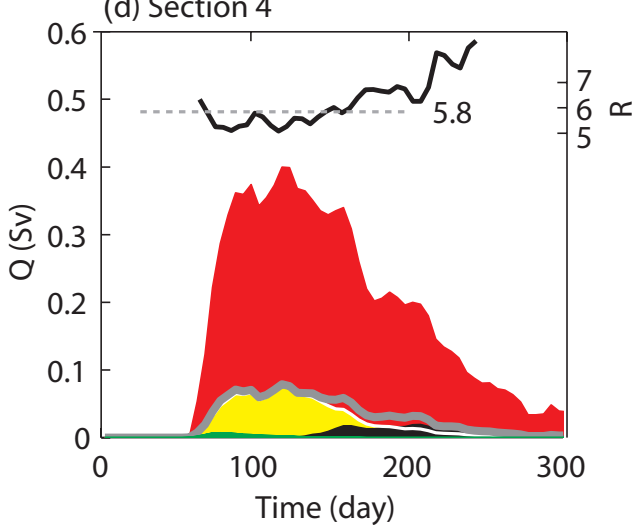

Fig. 11. Time series of volume transport of the overflow, $Q$ (red), calculated from 5-daily averaged data for (a) Sect. 1, (b) Sect. 2, (c) Sect. 3 and (d) Sect. 4, for the 300 days of the simulation. Transport associated with each tracer is shown separately: green, $Q_{T R 0}$; yellow, $Q_{T R 1}$; black, $Q_{T R 2}$. Thick gray trace is $Q_{T R}=Q_{T R 0}+Q_{T R 1}+Q_{T R 2}$. The ratio $R=Q / Q_{T R}$ is shown (black trace, right axis) for the first 200 days, with the mean values indicated. Note that the axis limits for both $Q$ and $R$ differ between panels.

density difference between the plume and the ambient water is of main importance. In the present study, this depends on the prescribed properties of the plume water. In a more realistic setting, the density structure of the ambient water will depend on the inflow of Atlantic and Arctic water masses across the open boundaries. The model results accordingly suffer from the lack of the mean oceanic circulation and the effect of winds and tides.

\subsection{Entrainment and detrainment}

A major part of our understanding of entrainment has been achieved through laboratory experiments in homogenous fluids and during the transient stage of a bottom gravity current plume $^{3}$ (Turner, 1986; Simpson, 1987). Recent experiments, again during the transient stage, of dense water flow on an

\footnotetext{
${ }^{3}$ For example, head and tail development of a gravity current after the immediate release of a constant volume dense fluid, or during supply of continuous dense fluid volume flux for a finite period of time until the dense water accumulated at the bottom of a typically small tank starts affecting the gravity current dynamics.
}

inclined surface into stratified ambient emphasized the importance of detrainment (Baines, 2001) and internal waves (Monaghan, 2007). Furthermore, most of the experiments have been conducted on very steep slopes to achieve sufficient turbulence and mixing. Environmental gravity currents observed in the nature, however, are typically in an equilibrium state and especially in the ocean on gentler slopes likely resulting in different gravity current dynamics and entrainment characteristics. Therefore numerous entrainment parameterizations have been suggested (Fernando, 1991), typically as a function of local Froude number (or overall Richardson number) or bottom slope, none of which satisfactorily captures the entrainment in geophysical gravity currents. Canuto et al. (2005) proposed an expression which incorporates local (along the flow) and non-local models in addition to double diffusive effects that can be important in the absence of shear. Recently, Arneborg et al. (2007) reported on the longest-ever $(19 \mathrm{~h})$ time series of direct turbulence measurements in a quasi-steady gravity current which suggest a dependence on both Froude and Ekman numbers. 


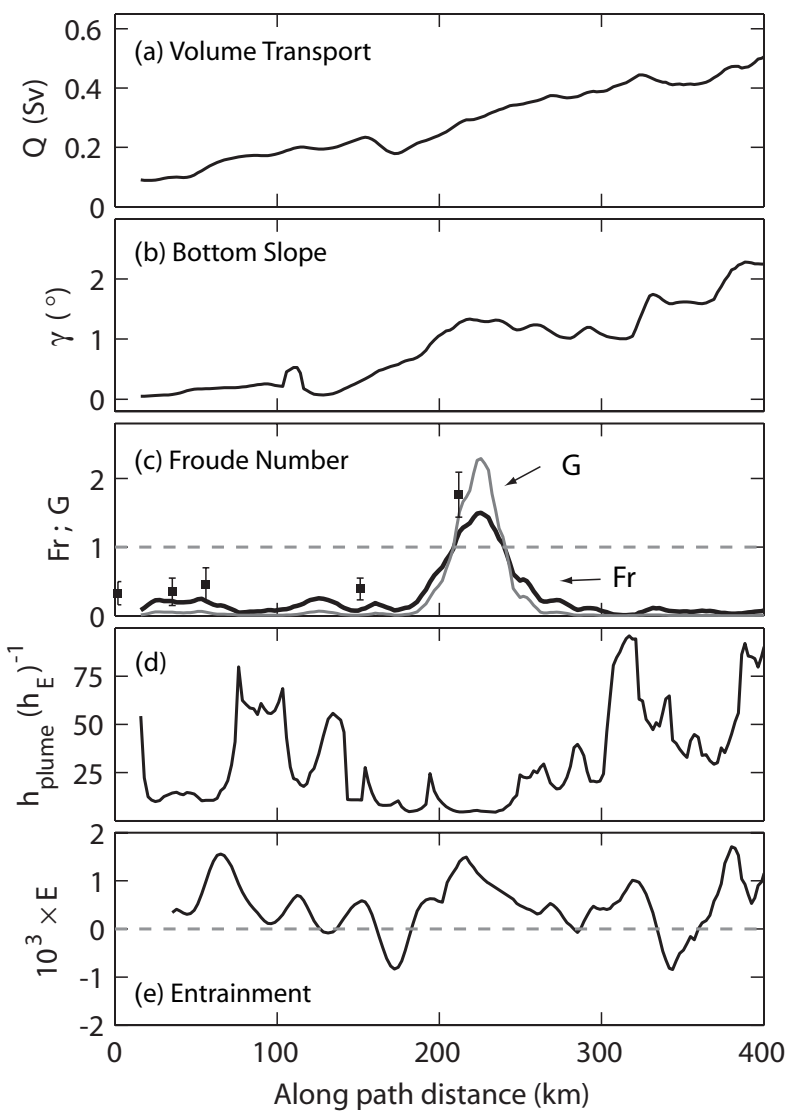

Fig. 12. Along path evolution, at day 150 , of (a) overflow volume transport, $Q$, (b) bottom slope $(\gamma)$, (c) local Froude number, $F r$, and (gray) local two-layer Froude number, $G(\mathbf{d})$ plume thickness normalized by the Ekman layer thickness $\left(h_{E}\right)$ and (e) the entrainment coefficient, $E$. Negative values of $E$ indicate detrainment. Data points (squares) and errorbars shown in (c) are the mean and standard deviation, respectively, of $\mathrm{Fr}$ derived using daily station data (stations 3 to 7) over 10 day window centered at day 150.

The along path evolution of slope or Froude number ( $\mathrm{Fr}$ or $G$ ) shows no clear correlation with entrainment (Fig. 12). Typical parameterizations would lead to significant entrainment only at around $200 \mathrm{~km}$ downstream of the sill where $F r>1$ and mixing would be absent for the rest of the path (Fig. 14). This is clearly not the case as evidenced from direct dissipation measurements in Storfjordrenna and significantly large $E$ inferred from the model results. Entrainment values around $F r=1$ are in general agreement with typical $E$ - $F r$ relations (curves 1-4, Fig. 14), and for $0.5<F r<1$ the model data approach the relation $E=1 \times 10^{-3} \mathrm{Fr}^{2}$ (Fernando, 1991). For a comparatively low $\mathrm{Fr}$ regime, direct dissipation measurements of Arneborg et al. (2007) suggested $E$ ( $F r=0.54$; $E=6.6 \times 10^{-5}$ ) that compared better with curve 2 (Cenedese et al., 2004). For smaller $\mathrm{Fr}$ the plume is characterized by entrainment at least an order of magnitude larger than that predicted by various suggested relations.
The entrainment is an integrated result of instantaneous instabilities which will be under-represented when evaluated with $\mathrm{Fr}$ from the 10-day averaged fields of day 150. Local, high-frequency $\mathrm{Fr}$ can be larger at times and will lead to mixing that will contribute to the inferred entrainment coefficient. Froude numbers derived using the model station data (daily snapshots), when averaged within \pm 10 days of day 150 are significantly larger (squares and errorbars in Fig. 12c) than those derived from the 10-day averaged field. Daily snapshots are not sufficiently sampled; hence a bias towards lower $F r$ is still likely. Furthermore, we emphasize that entrainment coefficient diagnosed here includes both the actual mixing imposed by the turbulence closure and the artificial numerical diffusion, which will bias the entrainment large. Deliberately running experiments without any turbulence closure in a z-level model Riemenschneider and Legg (2007) showed that in the Faroe Bank Channel overflow, numerical mixing alone lead to plume structure and entrainment comparable to observations. Although this effect will be comparatively small in the terrain-following coordinate used here, the entrainment coefficients should be regarded with caution. The non-local model of Canuto et al. (2005) predict roughly comparable values for low $F r$. We conclude that the high entrainment rates for $F r<0.5$ might be influenced by undersampling of $\mathrm{Fr}$ through the use of 10 day average fields, non-local effects, and numerical diffusion.

7.3 Rotating hydraulics, rotational control and interface characteristics

Contraction of currents by topographic features such as sill and straits can, in favorable conditions, lead to a hydraulic (critical) control and make it possible to estimate volume transport across the sill from simple measurements in the basin (Gill, 1977; Whitehead, 1998). In rotating hydraulics, the ability of a long wave (typically Kelvin wave), to propagate upstream defines the criticality and can be assessed by the Froude number which should be supercritical over the whole cross-section (Pratt and Helfrich, 2005; Girton et al., 2006), i.e. local supercritical values of the Froude number are not sufficient.

Estimates of transport assuming rotational hydraulic control have been reported for the Storfjorden sill (e.g. Skogseth et al., 2005b). Our model results can be used to discuss whether such relations are applicable to the site. For a deep upstream basin with negligible upstream velocities, the maximum transport across a rectangular cross-section, ignoring friction and assuming zero potential vorticity, is

$Q_{W L K}=\frac{g^{\prime} h_{u}^{2}}{2 f}$

when the channel width, $W$, is larger than the internal Rossby radius (Whitehead et al., 1974). Here, $h_{u}$ is the elevation above the sill level of the dense layer in the basin. Storfjorden sill cross-section is approximately rectangular with 

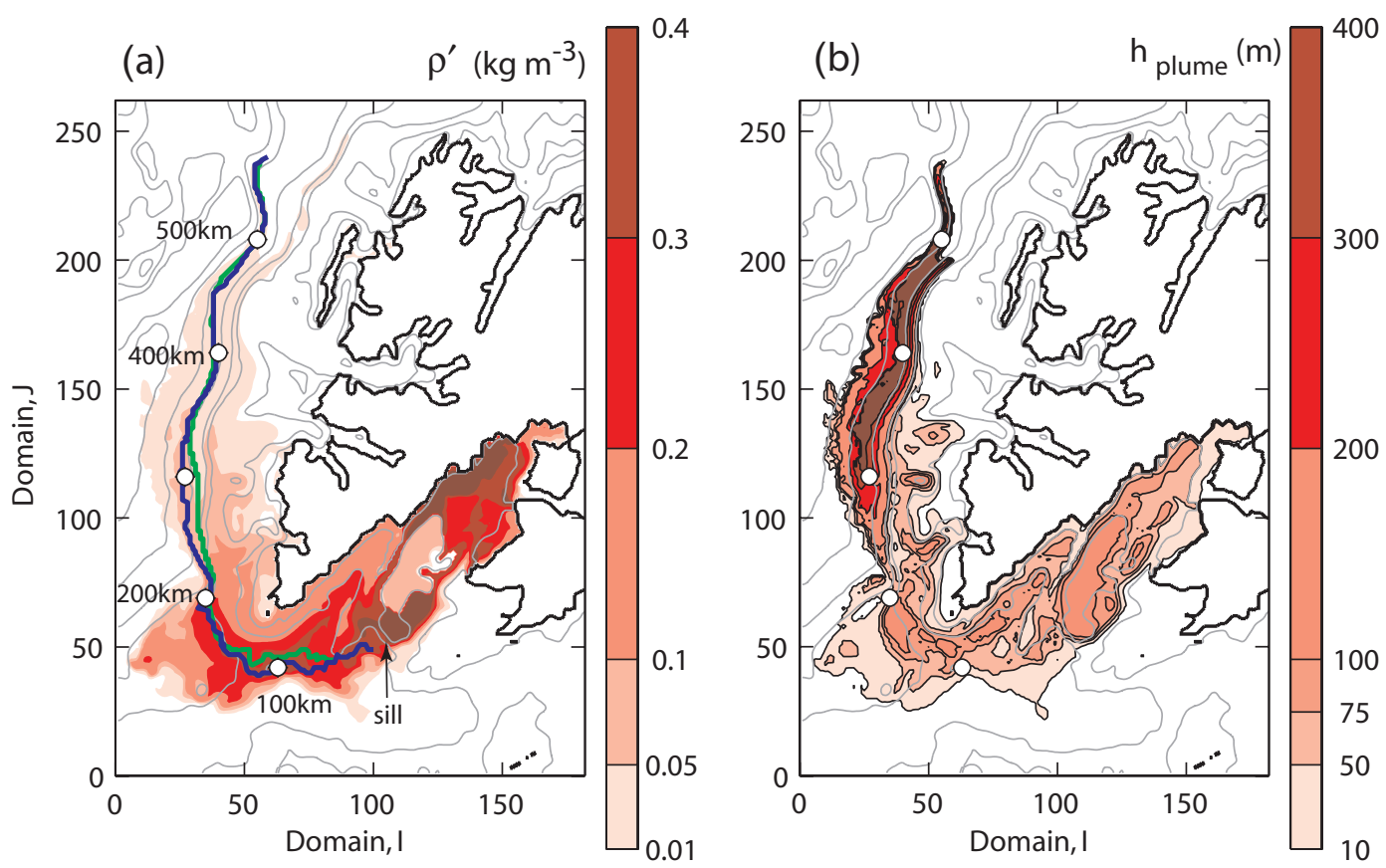

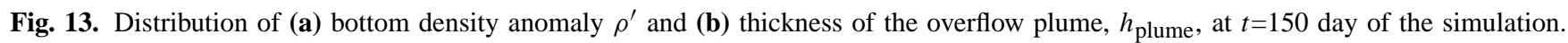
Isobaths are drawn for 50,120, 300 m and at $500 \mathrm{~m}$ intervals between 500 and $2500 \mathrm{~m}$ (gray). Sill is indicated by an arrow. In (a), the path of the overflow at day 150 (blue) is compared to the path derived from a constant descent rate of 1/400 (Killworth, 2001; green trace). White bullets are placed at $100 \mathrm{~km}$ intervals along the path.

$W \sim 40 \mathrm{~km}$, crossing the $75 \mathrm{~m}$ to $120 \mathrm{~m}$ isobaths in the first $5 \mathrm{~km}$, relatively flat for $30 \mathrm{~km}$ and reaching the $75 \mathrm{~m}$ isobath in the next $12 \mathrm{~km}$. Potential vorticity,

$q=(f+\xi) / H$

where $H$ is the water depth and $\xi$ is the relative vorticity

$\xi=\frac{\partial v}{\partial x}-\frac{\partial u}{\partial y}$

is small and relatively constant in the basin $q=2$ $( \pm 1) \times 10^{-6} \mathrm{~m} \mathrm{~s}^{-1}$. However, Froude number $(F, G$ or semigeostrophic Froude number, Gill, 1977) in the vicinity of the sill derived over $65 \mathrm{~km}$ wide cross-sections within $\pm 30 \mathrm{~km}$ of the sill is never above unity, suggesting that rotational hydraulic control is not expected for the Storfjorden overflow. At the sill, local $\mathrm{Fr}$ decreases from a maximum of 0.75 to 0.03 within $12 \mathrm{~km}$ of the western wall (75 m isobath), suggesting that retarding stress that balances the pressure gradient is mainly the bottom stress whereas entrainment stress is not a significant part of the total stress. When normalized by the internal Rossby radius $R_{o}=\sqrt{g^{\prime} h_{u}} / f$ derived using $h_{u}=55 \mathrm{~m}$ of the model bathymetry, $W$ is 20 to 8 times $R_{o}$ in the $\pm 30 \mathrm{~km}$ range from the basin to downstream of the sill. The weir relation, Eq. (5), predicts 3.4 times the modeled volume transport across the sill in the second half of the experiment.

The sill is wide such that geostrophy can control the tilt of the plume interface. For a two-layered system with vertical

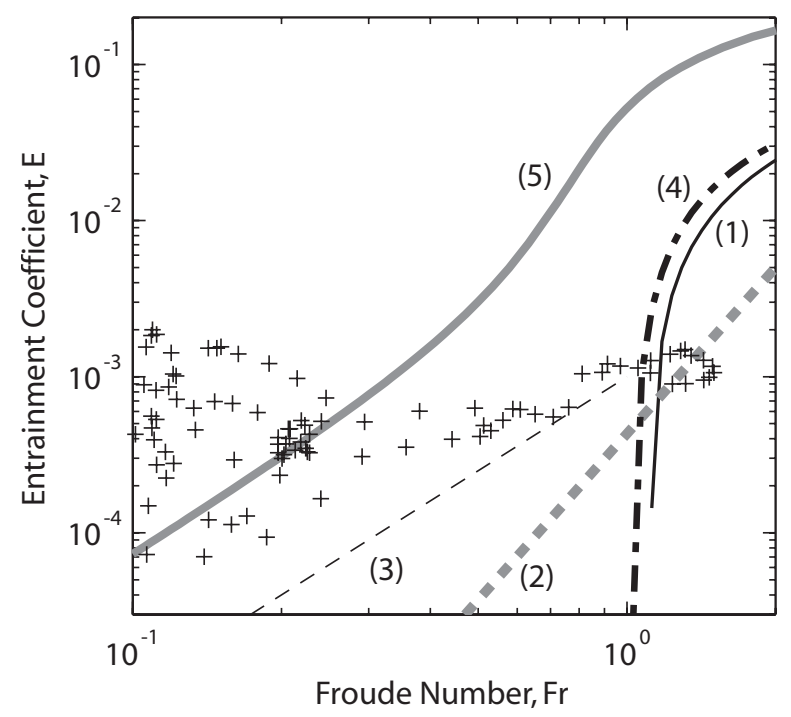

Fig. 14. Entrainment coefficient $E$, versus local Froude number $F r$. Data points (crosses) are derived from model cross-sections along the path of the plume using Eq. (3) with $F r$ evaluated at the core of the plume. Curves shown are (1) Ellison and Turner (1959); (2) Cenedese et al. (2004); (3) Fernando (1991); (4) local and (5) nonlocal model of Canuto et al. (2005). The non-local model is derived using the parameters given in Fig. 2 of Canuto et al. (2005). 

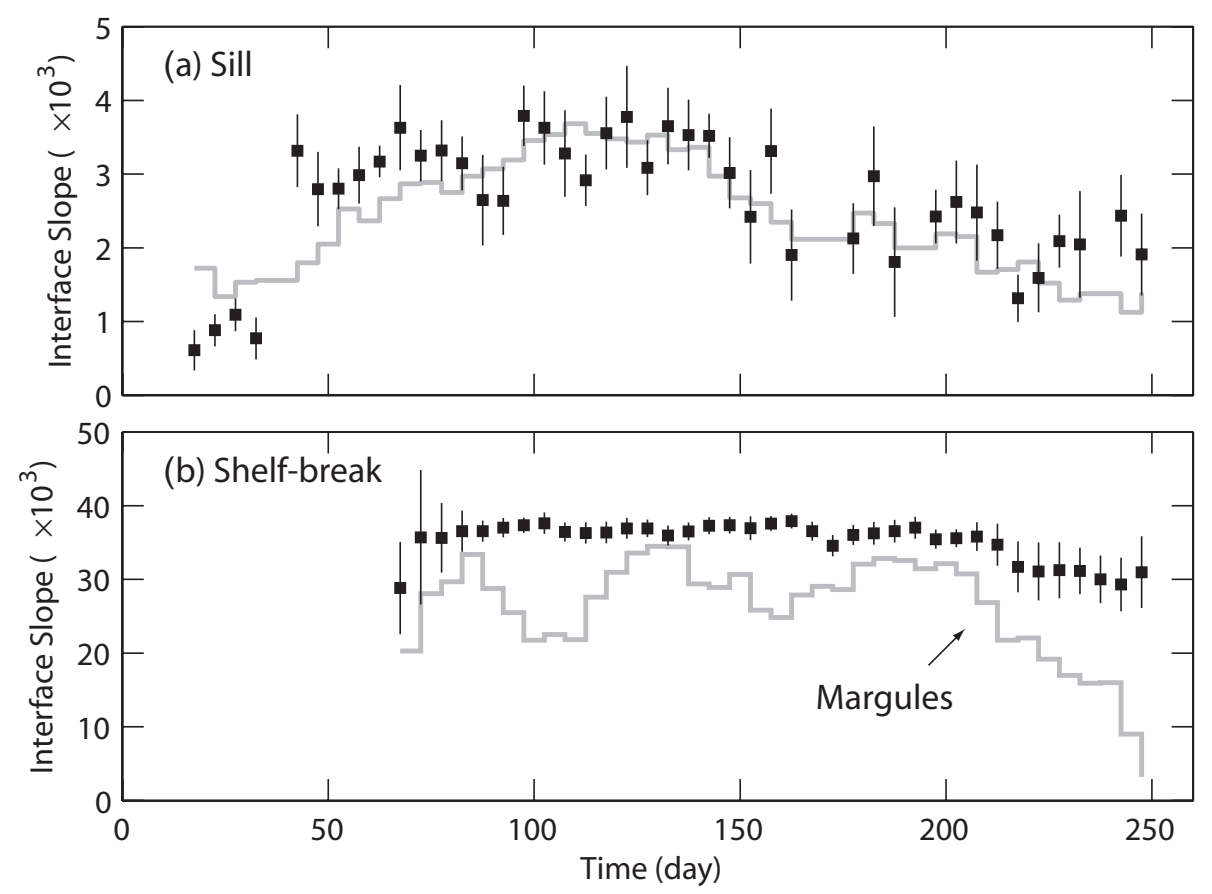

Fig. 15. The interface slope derived from the model results (filled squares) and the Margules relation Eq. (8) (gray) for (a) the sill section (Sect. 1) and (b) the shelf-break section (Sect. 4). The interface slope is calculated by regressing the individual plume thickness against along section distance. Errorbars are the $95 \%$ confidence intervals.

difference in longitudinal velocity, $\Delta \mathrm{u}$, and density difference $\Delta \rho$, the Margules relation gives the interface slope as

$$
\frac{\Delta z}{\Delta y}=-\frac{\Delta u}{g^{\prime} / f}
$$

where $z$ and $y$ are the vertical coordinate and lateral coordinates, respectively. The interface slope at the sill can be captured by the Margules relation (Fig. 15a). For a rectangular cross-section, the volume transport through the triangular area defined by the core plume thickness, flat bottom and the interface given by Eq. (8) is $Q_{W L K}$ (Eq. 5) but with $h_{u}$ replaced by $h_{\text {plume }}$. This modification predicts the modeled volume transport at the sill across Sect. 1 within 10\% in the last half of the experiment (after the forcing has ceased) and within $40 \%$ over the whole duration of the experiment.

At the shelf-break (model Sect. 4), about $265 \mathrm{~km}$ downstream of the sill, the plume interface slope is an order of magnitude larger than that at the sill (Fig. 15b). Here, the bottom slope is comparatively steeper than the near sill region (Fig. 12b) and $F r$ is elevated. The steep slope causes a large pressure force where the overflow first crosses the continental slope, especially at about $J=80$ (Fig. 3b) where $F r$ reaches its maximum, about $40 \mathrm{~km}$ before Sect. $4(J=100)$. In response, the plume accelerates and both the bottom stress and entrainment stress become significant in the total stress. The geostrophy, however, is again decisive to the first order but the Margules relation underestimates the interface slope and shows larger variability (Fig. 15b). The discrep- ancy is mostly due to the adiabatic processes encountered at the steep slope.

\section{Concluding remarks}

The overflow of dense shelf water from Storfjorden in Svalbard is studied in an idealized 3-D set-up using ROMS. This study is the first 3-D numerical experiment of the Storfjorden overflow. A realistic brine forcing inferred from observations is applied synthetically in the upstream basin, and the focus is kept at the sill region and downstream. The pathway of the overflow, its descent and evolving water mass properties due to mixing are examined. Available observational data are used to evaluate the performance of the model. The model overflow compared favorably to the salient features of the overflow hydrography and captured the mean and variability of currents measured at the sill. Furthermore, eddy diffusivity profiles contrasted to those inferred from the direct turbulence (dissipation) measurements give confidence on the skill of the Mellor Yamada scheme in representing subgrid scale mixing for the Storfjorden overflow, and probably for gravity current modeling, in general.

The trough Storfjordrenna, downstream of the sill, is a relatively flat shelf which the plume encounters for the first $\sim 200 \mathrm{~km}$ of its path, before it reaches the shelf break. Reaching the shelf break, the plume narrows, accelerates with bottom speed reaching $0.6 \mathrm{~m} \mathrm{~s}^{-1}$, yielding local Froude number 
in excess of unity. In the vicinity of the sill and in Storfjordrenna the overflow is characterized by low Froude number dynamics, but with significant entrainment. The volume flux of the plume approximately doubles from the sill to the mouth of Storfjordrenna and increases by five-fold after crossing the shelf-break. In addition to the expected spill of dense plume over the sill, a significant amount of dense water flows over the ridge between the sill and Spitsbergen and fills into the trench north of the main axis of Storfjordrenna. This pattern was also observed in the simulation of Skogseth et al. (2008) ${ }^{1}$ suggesting that it is not an artifact of the idealized forcing. The two-branch evolution of the plume reported by Jungclaus et al. (1995) was not reproduced and the discrepancy is attributed to the relatively coarse bathymetry employed in Jungclaus et al. (1995).

The Storfjorden sill is not a critical contraction for the overflow and simplified weir transport relations assuming rotational hydraulic control are not applicable. To the leading order, geostrophy establishes the lateral slope of the plume interface at the sill that can be approximated by the Margules relation. This allows for a transport estimate that is consistent with the model results by evaluating the weir relation at the sill.

The terrain-following coordinates of ROMS - together with the Mellor-Yamada level $21 / 2$ turbulence closure - is found to be suitable for the Storfjorden overflow modeling. Subsequent studies employing realistic external forcing including coupled-ice model, tides and realistic stratification are merited to accurately evaluate the importance of the Storfjorden overflow's contribution to the Fram Strait and possibly to the Arctic Ocean.

Acknowledgements. This work has been funded by grant $155923 / 700$ from the Research Council of Norway under the project Polar Ocean Climate Processes (ProClim). We thank the reviewers for their constructive comments on the manuscript. This is publication no. A 187 from the Bjerknes Centre for Climate Research.

Edited by: J. M. Huthnance

\section{References}

Aagaard, K., Coachman, L. K., and Carmack, E.: On the halocline of the Arctic Ocean, Deep-Sea Res., 28A, 529-545, 1981.

Anderson, L. G., Falck, E., Jones, E. P., Jutterström, S., and Swift, J. $\mathrm{H}$.: Enhanced uptake of atmospheric $\mathrm{CO}_{2}$ during freezing of seawater: A field study in Storfjorden, Svalbard, J. Geophys. Res., 109, C06004, doi:06010.01029/02003JC002120, 2004.

Arneborg, L., Fiekas, V., Umlauf, L., and Burchard, H.: Gravity currents and entrainment- a process study based on observations in the Arkona Basin, J. Phys. Oceanogr., 37, 2094-2113, 2007.

Baines, P. G. and Condie, S.: Observations and modelling of Antarctic downslope flows: a review, in: Ocean, ice and atmosphere: interactions at the Antarctic continental margin, Antarctic Research Series, American Geophysical Union, 29-49, 1998.
Baines, P. G.: Mixing in flows down gentle slopes into stratified environments, J. Fluid Mech., 443, 237-270, 2001.

Canuto, V. M., Dubovikov, M. S., and Cheng, Y.: Entrainment: Local and non-local turbulence models with double diffusion, Geophys. Res. Lett., 32, L22604, doi:22610.21029/22005GL023771, 2005.

Cenedese, C., Whitehead, J. A., Ascarelli, T. A., and Ohiwa, M.: A dense current flowing down a sloping bottom in a rotating fluid, J. Phys. Oceanogr., 34, 188-203, 2004.

Conkright, M. E., Locarnini, R. A., Garcia, H. E., O’Brien, T. D., Boyer, T. P., Stephens, C., and Antonov, J. I.: World Ocean Atlas 2001: Objective Analyses, Data Statistics, and Figures, CDROM Documentation. National Oceanographic Data Center, Silver Spring, MD, 17 pp., 2002.

Dickson, R. and Brown, J.: The production of North-Atlantic deep water - sources, rates and pathways, J. Geophys. Res., 99, 12 139-12 341, 1994

Ellison, T. H. and Turner, J. S.: Turbulent entrainment in stratified flows, J. Fluid Mech., 6, 423-448, 1959.

ETOPO2: U.S. Department of Commerce, National Oceanic and Atmospheric Administration, National Geophysical Data Center. 2-minute gridded Global Relief Data (ETOPO2), http://www. ngdc.noaa.gov/mgg/fliers/01mgg04.html, 2001.

Ezer, T., Arango, H., and Shchepetkin, A. F.: Developments in terrain-following ocean models: inter-comparisons of numerical aspects, Ocean Modell., 4, 249-267, 2002.

Ezer, T.: Entrainment, diapycnal mixing and transport in threedimensional bottom gravity current simulations using the MellorYamada turbulence scheme, Ocean Modell., 9, 151-168, 2005.

Fer, I., Lemmin, U., and Thorpe, S. A.: Cascading of water down the sloping sides of a deep lake in winter, Geophys. Res. Lett., 28, 2093-2096, 2001.

Fer, I., Skogseth, R., Haugan, P. M., and Jaccard, P.: Observations of the Storfjorden overflow, Deep-Sea Res. I, 50, 1283-1303, 2003.

Fer, I., Skogseth, R., and Haugan, P. M.: Mixing of the Storfjorden overflow (Svalbard Archipelago) inferred from density overturns, J. Geophys. Res., 109, C01005, doi:01010.01029/02003JC001968, 2004.

Fer, I.: Scaling turbulent dissipation in an Arctic fjord, Deep-Sea Res. II, 53, 77-95, 2006.

Fernando, H. J. S.: Turbulent mixing in stratified flows, Annu. Rev. Fluid Mech., 23, 455-493, 1991.

Gill, A. E.: The hydraulics of rotating-channel flow, J. Fluid Mech., 80, 641-671, 1977.

Girton, J. B., Pratt, L. J., Sutherland, D. A., and Price, J. F.: Is the Faroe Bank Channel overflow hydraulically controlled?, J. Phys. Oceanogr., 36, 2340-2349, 2006.

Gordon, A. L., Visbeck, M., and Huber, B.: Export of Weddell Sea deep and bottom water, J. Geophys. Res., 106, 9005-9017, 1998.

Griffiths, R. W.: Gravity currents in rotating systems, Annu. Rev. Fluid. Mech., 18, 59-89, 1986.

Haarpaintner, J., Gascard, J.-C., and Haugan, P. M.: Ice production and brine formation in Storfjorden, Svalbard, J. Geophys. Res., 106, 14 001-14 013, 2001.

Jungclaus, J. H., Backhaus, J. O., and Fohrmann, H.: Outflow of dense water from the Storfjord in Svalbard: A numerical model study, J. Geophys. Res., 100, 24 719-24 728, 1995.

Killworth, P. D.: Mixing of the Weddell Sea continental slope, 
Deep-Sea Res., 24, 427-448, 1977.

Killworth, P. D.: On the rate of descent of overflows, J. Geophys. Res., 106, 22 267-22 275, 2001.

Lane-Serff, G. F. and Baines, P. G.: Eddy formation by dense flows on slopes in a rotating fluid, J. Fluid Mech., 363, 229-252, 1998.

Legg, S., Hallberg, R. W., and Girton, J. B.: Comparison of entrainment in overflows simulated by z-coordinate, isopycnal and non-hydrostatic models, Ocean Modell., 11, 69-97, 2006.

Monaghan, J. J.: Gravity current interaction with interfaces, Annu. Rev. Fluid Mech., 39, 245-261, 2007.

Osborn, T. R.: Estimates of the local rate of vertical diffusion from dissipation measurements, J. Phys. Oceanogr., 10, 83-89, 1980.

Pratt, L. J. and Helfrich, K. R.: Generalized conditions for hydraulic criticality of oceanic overflows, J. Phys. Oceanogr., 35, 17821800, 2005.

Price, J. F. and Baringer, M. O.: Outflows and deep water production by marginal seas, Prog. Oceanogr., 33, 161-200, 1994.

Quadfasel, D., Rudels, B., and Kurz, K.: Outflow of dense water from a Svalbard fjord into the Fram Strait, Deep-Sea Res., 35, 1143-1150, 1988.

Riemenschneider, U. and Legg, S.: Regional simulations of the Faroe Bank Channel overflow in a level model, Ocean Modell., 2007, 93-122, 2007.

Rudels, B. and Quadfasel, D.: Convection and deep water formation in the Arctic Ocean - Greenland Sea system, J. Mar. Syst., 2, 435-450, 1991

Schauer, U. and Fahrbach, E.: A dense bottom water plume in the western Barents Sea: downstream modification and interannual variability, Deep-Sea Res., 46, 2095-2108, 1999.

Shchepetkin, A. F. and McWilliams, J. C.: A method for computing horizontal pressure-gradient force in an oceanic model with a non-aligned vertical coordinate, J. Geophys. Res., 108, 1-34, 2003.

Shchepetkin, A. F. and McWilliams, J. C.: The regional oceanic modeling system (ROMS): a split-explicit, free-surface, topography-following-coordinate oceanic model, Ocean Modell., 9, 347-404, 2005 .
Simpson, J. E.: Gravity currents: in the environment and the laboratory, Ellis Horwood series in environmental science, edited by: Scorer, R. S., Ellis Horwood Limited, Chichester, 244 pp., 1987.

Skogseth, R., Haugan, P. M., and Haarpaintner, J.: Ice and brine production in Storfjorden from four winters of satellite and in situ observations and modelling, J. Geophys. Res., 109, C10008, doi:10010.11029/12004JC002384, 2004.

Skogseth, R., Fer, I., and Haugan, P. M.: Dense-water production and overflow from an Arctic coastal polynya in Storfjorden, in: The Nordic Seas: An Integrated Perspective, edited by: Drange, H., Dokken, T. M., Furevik, T., Gerges, R., and Berger, W., AGU Geophysical Monograph, 158, 73-88, 2005a.

Skogseth, R., Haugan, P. M., and Jakobsson, M.: Water mass transformations in Storfjorden, Cont. Shelf Res., 25, 667-695, 2005b.

Song, T. and Haidvogel, D.: A semi-implicit ocean circulation model using a generalized topography-following coordinate system, J. Comput. Phys., 115, 228-244, 1994.

Sternberg, R. W., Aagaard, K., Cacchione, D., Wheatcroft, R. A., Beach, R. A., Roach, A. T., and Marsden, M. A. H.: Long-term near-bed observations of velocity and hydrographic properties in the northeast Barents Sea with implications for sediment transport, Cont. Shelf Res., 21, 509-529, 2001.

Turner, J. S.: Turbulent entrainment: the development of the entrainment assumption, and its application to geophysical flows, J. Fluid Mech., 173, 431-471, 1986.

Whitehead, J. A., Leetmaa, A., and Knox, R. A.: Rotating hydraulics of strait and sill flows, Geophys. Fluid Dyn., 6, 101-125, 1974.

Whitehead, J. A.: Topographic control of oceanic flows in deep passages and straits, Rev. Geophys., 36, 423-440, 1998. 